\title{
Phenological shifts of abiotic events, producers and consumers
} across a continent

\section{Roslin, Tomas}

2021-03

Roslin , T, Antao , L , Hällfors , M , Meyke , E , Lo , C , Tikhonov , G, Delgado , M D M , Gurarie , E , Abadonova , M , Abduraimov, O , Adrianova , O, Akimova , T, Akkiev, M , Ananin , A , Andreeva , E , Andriychuk , N , Antipin , M , Arzamascev , K, Babina , S , Babushkin, M , Bakin , O, Barabancova , A, Basilskaja, I , Belova, N, Belyaeva , N , Bespalova, T , Bisikalova , E, Bobretsov, A, Bobrov, V , Bobrovskyi , V , Bochkareva , E , Bogdanov, G, Bolshakov, V , Bondarchuk, S, Bukharova , E, Butunina , A, Buyvolov , Y , Buyvolova , A, Bykov , Y, Chakhireva , E , Chashchina, O , Cherenkova, N, Chistjakov , S, Chuhontseva , S, Davydov, E A, Demchenko, V , Diadicheva, E, Dobrolyubov, A, Dostoyevskaya , L , Drovnina , S , Drozdova , Z, Dubanaev, A, Dubrovsky, Y, Elsukov , S , Epova , L , Ermakova , O S , Ermakova , O S , Ershkova , E , Esengeldenova , A , Evstigneev, O , Fedchenko , I, Fedotova , V , Filatova , T, Gashev , S, Gavrilov , A , Gaydysh , I, Golovcov , D , Goncharova , N, Gorbunova , E , Gordeeva , T , Grishchenko , V , Gromyko , L , Hohryakov , V , Hritankov , A , Ignatenko, E , Igosheva , S , Ivanova , U , Ivanova , N, Kalinkin , Y, Kaygorodova , E, Kazansky , F , Kiseleva , D , Knorre , A , Kolpashikov , L , Korobov , E , Korolyova , H , Korotkikh , N , Kosenkov , G, Kossenko , S , Kotlugalyamova, E, Kozlovsky, E, Kozsheechkin, V, Kozurak , A, Kozyr , I, Krasnopevtseva , A, Kruglikov, S , Kuberskaya , O , Kudryavtsev , A, Kulebyakina, E , Kulsha, Y, Kupriyanova , M , Kurbanbagamaev, M , Kutenkov, A, Kutenkova, N , Kuyantseva , N , Kuznetsov , A , Larin , E , Lebedev , P , Litvinov , K , Luzhkova , N , Mahmudov, A, Makovkina, L, Mamontov, V , Mayorova , S, Megalinskaja , I, Meydus , A , Minin , A, Mitrofanov , O , Motruk, M , Myslenkov, A, Nasonova, N, Nemtseva, N , Nesterova , I, Nezdoliy , T , Niroda , T , Novikova , T , Panicheva, D , Pavlov , A, Pavlova , K, Podolski , S , Polikarpova , N, Polyanskaya , T , Pospelov , I , Pospelova , E, Prokhorov , I , Prokosheva , I, Puchnina , L, Putrashyk , I, Raiskaya , J, Rozhkov , Y, Rozhkova , O , Rudenko, M , Rybnikova , I, Rykova , S , Sahnevich , M , Samoylov , A , Sanko , V , Sapelnikova , I, Sazonov , S, Selyunina, Z, Shalaeva, K, Shashkov, M , Shcherbakov , A , Shevchyk, V, Shubin , S, Shujskaja , E, Sibgatullin, R, Sikkila , N, Sitnikova, E, Sivkov , A, Skok, N, Skorokhodova , S , Smirnova, E, Sokolova, G, Sopin, V, Spasovski , Y, Stepanov, S , Stratiy , V , Strekalovskaya , V , Sukhov, A, Suleymanova , G , Sultangareeva , L , Teleganova , V , Teplov , V , Teplova , V , Tertitsa , T , Timoshkin , V , Tirski, D , Tolmachev , A , Tomilin , A , Tselishcheva , L, Turgunov , M , Tyukh , Y, Van , P , Van , V , Vasin , A, Vasina, A, Vekliuk, A, Vetchinnikova, L, Vinogradov, V, Volodchenkov , N , Voloshina , I , Xoliqov , T , Yablonovska-Grishchenko , E , Yakovlev , V , 


\section{Phenological shifts of abiotic events, producers and consumers across a continent}

\section{Authors:}

Tomas Roslin ${ }^{1}$, Laura Antao $^{2}$, Maria Hällfors $^{2}$, Evgeniy Meyke ${ }^{3}$, Coong Lo ${ }^{2}$, Gleb Tikhonov $^{4}$, Maria del Mar Delgado ${ }^{5}$, Eliezer Gurarie ${ }^{6}$, Marina Abadonova ${ }^{7}$, Ozodbek Abduraimov $^{8}$, Olga Adrianova $^{9}$, Tatiana Akimova ${ }^{10}$, Muzhigit Akkiev ${ }^{11}$, Aleksandr Ananin ${ }^{12,13}$, Elena Andreeva ${ }^{14}$, Natalia Andriychuk ${ }^{15}$, Maxim Antipin ${ }^{16}$, Konstantin Arzamascev ${ }^{17}$, Svetlana Babina ${ }^{18}$, Miroslav Babushkin $^{19}$, Oleg Bakin ${ }^{20}$, Anna Barabancova ${ }^{21}$, Inna Basilskaja ${ }^{22}$, Nina Belova ${ }^{23}$, Natalia Belyaeva $^{24}$, Tatjana Bespalova ${ }^{25}$, Evgeniya Bisikalova ${ }^{26}$, Anatoly Bobretsov ${ }^{27}$, Vladimir Bobrov ${ }^{28}$, Vadim Bobrovskyi ${ }^{29}$, Elena Bochkareva ${ }^{30,31}$, Gennady Bogdanov ${ }^{32}$, Vladimir Bolshakov ${ }^{33}$, Svetlana Bondarchuk $^{34}$, Evgeniya Bukharova ${ }^{12,102}$, Alena Butunina ${ }^{25}$, Yuri Buyvolov ${ }^{35}$, Anna Buyvolova ${ }^{36}$, Yuri Bykov $^{37}$, Elena Chakhireva ${ }^{20}$, Olga Chashchina ${ }^{38}$, Nadezhda Cherenkova ${ }^{39}$, Sergej Chistjakov $^{40}$, Svetlana Chuhontseva ${ }^{10}$, Evgeniy A Davydov ${ }^{41,30}$, Viktor Demchenko ${ }^{42}$, Elena Diadicheva $^{42}$, Aleksandr Dobrolyubov ${ }^{43}$, Ludmila Dostoyevskaya ${ }^{44}$, Svetlana Drovnina ${ }^{39}$, Zoya Drozdova $^{37}$, Akynaly Dubanaev ${ }^{45}$, Yuriy Dubrovsky ${ }^{46}$, Sergey Elsukov $^{34}$, Lidia Epova $^{47}$, Olga Ermakova $^{23}$, Olga S Ermakova ${ }^{48}$, Elena Ershkova ${ }^{49,50}$, Aleksandra Esengeldenova ${ }^{25}$, Oleg Evstigneev $^{51}$, Irina Fedchenko ${ }^{52}$, Violetta Fedotova ${ }^{44}$, Tatiana Filatova ${ }^{53}$, Sergey Gashev $^{54}$, Anatoliy Gavrilov $^{55}$, Irina Gaydysh ${ }^{9}$, Dmitrij Golovcov ${ }^{56}$, Nadezhda Goncharova $^{14}$, Elena Gorbunova ${ }^{10}$, Tatyana Gordeeva ${ }^{57,102}$, Vitaly Grishchenko ${ }^{58}$, Ludmila Gromyko ${ }^{34}$, Vladimir Hohryakov ${ }^{59}$, Alexander Hritankov ${ }^{14}$, Elena Ignatenko ${ }^{60}$, Svetlana Igosheva ${ }^{61}$, Uliya Ivanova ${ }^{62}$, Natalya Ivanova ${ }^{63}$, Yury Kalinkin ${ }^{10}$, Evgeniya Kaygorodova ${ }^{51}$, Fedor Kazansky ${ }^{64}$, Darya Kiseleva ${ }^{65}$, Anastasia Knorre $^{14,66}$, Leonid Kolpashikov ${ }^{55}$, Evgenii Korobov ${ }^{67}$, Helen Korolyova ${ }^{10}$, Natalia Korotkikh ${ }^{25}$,

Gennadiy Kosenkov $^{59}$, Sergey Kossenko ${ }^{51}$, Elvira Kotlugalyamova ${ }^{68}$, Evgeny Kozlovsky $^{69}$, Vladimir Kozsheechkin ${ }^{14}$, Alla Kozurak ${ }^{15}$, Irina Kozyr ${ }^{23}$, Aleksandra Krasnopevtseva ${ }^{23}$, Sergey 
Kruglikov $^{51}$, Olga Kuberskaya ${ }^{29}$, Aleksey Kudryavtsev ${ }^{43}$, Elena Kulebyakina ${ }^{70}$, Yuliia Kulsha ${ }^{58}$, Margarita Kupriyanova $^{62}$, Murad Kurbanbagamaev ${ }^{27}$, Anatoliy Kutenkov ${ }^{71}$, Nadezhda Kutenkova ${ }^{71}$, Nadezhda Kuyantseva ${ }^{38,72}$, Andrey Kuznetsov ${ }^{19}$, Evgeniy Larin ${ }^{25}$, Pavel Lebedev ${ }^{44,73}$, Kirill Litvinov $^{74}$, Natalia Luzhkova ${ }^{12}$, Azizbek Mahmudov ${ }^{8}$, Lidiya Makovkina ${ }^{75}$, Viktor Mamontov ${ }^{70}$, Svetlana Mayorova ${ }^{37}$, Irina Megalinskaja ${ }^{27}$, Artur Meydus ${ }^{76,77}$, Aleksandr Minin ${ }^{78,79}$, Oleg Mitrofanov $^{10}$, Mykhailo Motruk $^{80}$, Aleksandr Myslenkov ${ }^{75}$, Nina Nasonova $^{81}$, Natalia Nemtseva ${ }^{19}$, Irina Nesterova ${ }^{34}$, Tamara Nezdoliy ${ }^{62}$, Tatyana Niroda ${ }^{82}$, Tatiana Novikova ${ }^{61}$, Darya Panicheva ${ }^{64}$, Alexey Pavlov ${ }^{20}$, Klara Pavlova ${ }^{60}$, Sergei Podolski ${ }^{60}$, Natalja Polikarpova ${ }^{83}$, Tatiana Polyanskaya ${ }^{84}$, Igor Pospelov ${ }^{28}$, Elena Pospelova ${ }^{55}$, Ilya Prokhorov ${ }^{36}$, Irina Prokosheva ${ }^{85}$, Lyudmila Puchnina ${ }^{52}$, Ivan Putrashyk $^{82}$, Julia Raiskaya ${ }^{76}$, Yuri Rozhkov ${ }^{86}$, Olga Rozhkova ${ }^{86}$, Marina Rudenko ${ }^{87}$, Irina Rybnikova $^{19}$, Svetlana Rykova ${ }^{52}$, Miroslava Sahnevich $^{10}$, Alexander Samoylov ${ }^{39}$, Valeri Sanko ${ }^{42}$, Inna Sapelnikova ${ }^{22}$, Sergei Sazonov ${ }^{88,102}$, Zoya Selyunina ${ }^{89}$, Ksenia Shalaeva ${ }^{59}$, Maksim Shashkov ${ }^{90,63}$, Anatoliy Shcherbakov ${ }^{71}$, Vasyl Shevchyk ${ }^{58}$, Sergej Shubin ${ }^{91}$, Elena Shujskaja ${ }^{67}$, Rustam Sibgatullin ${ }^{24}$, Natalia Sikkila ${ }^{9}$, Elena Sitnikova ${ }^{51}$, Andrei Sivkov ${ }^{52,102}$, Nataliya Skok ${ }^{62}$, Svetlana Skorokhodova ${ }^{71}$, Elena Smirnova ${ }^{34}$, Galina Sokolova ${ }^{35}$, Vladimir Sopin ${ }^{76}$, Yurii Spasovski $^{92}$, Sergei Stepanov ${ }^{67}$, Vitaliy Stratiy $^{93}$, Violetta Strekalovskaya ${ }^{55}$, Alexander Sukhov ${ }^{71}$, Guzalya Suleymanova $^{94}$, Lilija Sultangareeva ${ }^{68}$, Viktorija Teleganova ${ }^{57}$, Viktor Teplov ${ }^{27,102}$, Valentina Teplova ${ }^{27}$, Tatiana Tertitsa ${ }^{27}$, Vladislav Timoshkin ${ }^{14}$, Dmitry Tirski ${ }^{86}$, Andrej Tolmachev $^{21}$, Aleksey Tomilin ${ }^{95,96}$, Ludmila Tselishcheva ${ }^{91}$, Mirabdulla Turgunov ${ }^{8}$, Yurij Tyukh ${ }^{82}$, Polina Van ${ }^{29}$, Vladimir Van ${ }^{29}$, Aleksander Vasin ${ }^{97}$, Aleksandra Vasina ${ }^{97}$, Anatoliy Vekliuk ${ }^{15}$, Lidia Vetchinnikova $^{88}$, Vladislav Vinogradov ${ }^{98}$, Nikolay Volodchenkov ${ }^{23}$, Inna Voloshina ${ }^{75}$, Tura Xoliqov $^{99}$, Eugenia Yablonovska-Grishchenko ${ }^{58}$, Vladimir Yakovlev ${ }^{10,102}$, Marina Yakovleva ${ }^{71}$, Oksana Yantser ${ }^{62}$, Yurij Yarema ${ }^{82}$, Andrey Zahvatov ${ }^{100}$, Valery Zakharov ${ }^{38}$, Nicolay Zelenetskiy ${ }^{19}$, Anatolii Zheltukhin ${ }^{67}$, Tatyana Zubina ${ }^{10}$, Juri Kurhinen ${ }^{2,88}$ \& Otso Ovaskainen ${ }^{2,101}$ 


\section{Affiliations:}

${ }^{1}$ Swedish University of Agricultural Sciences, Department of Ecology, PO BOX 7044, SE-75007

Uppsala, Sweden, ${ }^{2}$ University of Helsinki, PO BOX 6500014 Helsinki, Finland, ${ }^{3}$ EarthCape OY, Latokartanonkaari 300790 Helsinki, Finland, ${ }^{4}$ Department of Computer Science, Aalto University, PO Box 15400 FI-00076, Finland, ${ }^{5}$ Oviedo University, Research Unit of Biodiversity (UMIB, UOCSIC-PA), Campus Mieres, 33600 Mieres, Spain, ${ }^{6}$ University of Maryland, 3237 BiologyPsychology Building, University of Maryland, College Park, MD 20742, United States, ${ }^{7}$ National Park Orlovskoe Polesie, 303943, Orel region, Hotynetskiy district, Zhuderskiy village, Shkolnaya st. 2, Russian Federation, ${ }^{8}$ Institute of Botany, Academy of sciences of the Republic of Uzbekistan, 100053, Tashkent, Bogi shamol str. 232 V, Uzbekistan, ${ }^{9}$ Kostomuksha Nature Reserve, 186930, Karelia Republic, Kostomuksha, Priozernaya 2, Russian Federation, ${ }^{10}$ Altai State Nature Biosphere Reserve, 649000, Altai Republic, Gorno-Altaysk, Naberezhnyi st., 1, Russian Federation, ${ }^{11}$ Kabardino-Balkarski Nature Reserve, 360000, Kabardino-Balkaria, Cherek District, Mechieva 78, Russian Federation, ${ }^{12}$ FSE Zapovednoe Podlemorye, 671623, Republic of Buryatia, Ust-Bargizin, Lenina st. 71, Russian Federation, ${ }^{13}$ Institute of General and Experimental Biology, Siberian Department, Russian Academy of Sciences, 670047, Republic of Buryatia, Ulan-Ude, Sakhyanovoy str. 6, Russian Federation, ${ }^{14}$ State Nature Reserve Stolby, 660006, Krasnoyarsk region, Krasnoyarsk, Kariernaya 26, Russian Federation, ${ }^{15}$ Carpathian Biosphere Reserve, 90600, Zakarpatska obl., Rakhiv, Krasne Pleso Str. 77, Ukraine, ${ }^{16}$ Nizhne-Svirsky State Nature Reserve, 18700, Leningrad Region, Lodeinoe Pole, Svir River, 1, Russian Federation, ${ }^{17}$ State Nature Reserve Prisursky, 428034, Cheboksary, Lesnoj, 9, Russian Federation, ${ }^{18}$ Zapovednoe Pribajkalje (BajkaloLensky State Nature Reserve, Pribajkalsky National Park), 664050, Irkutsk, Bajkalskaya St., 291B, Russian Federation, ${ }^{19}$ Darwin Nature Biosphere Reserve, 162723, Cherepovets District, Vologda Region, Borok, 44, p/o Ploskovo, Russian Federation, ${ }^{20}$ Volzhsko-Kamsky National Nature 
Biosphere Rezerve, 422537, Tatarstan Republic, Zelenodolsk District, p/o Raifa, Sadovy, str. Vechova, 1, Russian Federation, ${ }^{21}$ FGBU National Park Shushenskiy Bor, 662710, Krasnoyarsk Region, Shushenskoe, Lugovaja 9, Russian Federation, ${ }^{22}$ Voronezhsky Nature Biosphere Reserve, 394080, Centralnaja usadba, Goszapovednik, Voronezh, Russian Federation, ${ }^{23}$ Baikalsky State Nature Biosphere Reserve, 671220, Buryatia Republic, Kabansky District, Tankhoy, 34 Krasnogvardeyskaya Street, Russian Federation, ${ }^{24}$ Visimsky Nature Biosphere Reserve, 624140, Kirovgrad, Stepana Razina, 23, Russian Federation, ${ }^{25}$ Kondinskie Lakes National Park named after L. F. Stashkevich, 628240, Hanty-Mansijsk district, City Sovietsky, Komsomolski st., 5, Russian Federation, ${ }^{26}$ FSBI United Administration of the Kedrovaya Pad' State Biosphere Nature Reserve and Leopard's Land National Park, 690068, Primorskiy kray, Vladivostok, pr. 100-letiya Vladivostoka 127, Russian Federation, ${ }^{27}$ Pechoro-Ilych State Nature Reserve, 169436, Komi Republic, Trinity-Pechora region, Yaksha, Laninoy Street 8, Russian Federation, ${ }^{28}$ A. N. Severtsov Institute of Ecology and Evolution, 119071, Moscow, Leninsky Prospect 33, Russian Federation, ${ }^{29}$ FGBU Zapovednoye Priamurye, Komsomolskiy Department, 681000, Khabarovskyi krai, Komsomolsk-on-Amur, Mira avenue, 54, Russian Federation, ${ }^{30}$ Tigirek State Nature Reserve, 656043, Barnaul, Nikitina street 111, Russian Federation, ${ }^{31}$ Institute of Systematics and Ecology of Animals of Siberian Branch of Russian Academy of Science, 930091, Novosibirsk, Frunze 11, Russian Federation, ${ }^{32}$ State Nature Reserve Bolshaya Kokshaga, 424038, Mary El Republic, Yoshkar-Ola, Voinov-Internacionalistov 26, Russian Federation, ${ }^{33}$ Institute of Plant and Animal Ecology, Ural Branch, Russian Academy of Sciences, 620100, Ekaterinburg, 8 Marta 202/3, Russian Federation, ${ }^{34}$ Sikhote-Alin State Nature Biosphere Reserve named after K. G. Abramov, 692150, Primorsky krai, Terney, Partizanskaya 44, Russian Federation, ${ }^{35}$ FSBI Prioksko-Terrasniy State Reserve, 142200, Moscow region, Serpukhov district, Danky, Russian Federation, ${ }^{36}$ Lomonosov Moscow State University, 119991, Moscow, Leninskie Gory, Russian 
97 Federation, ${ }^{37}$ National park Meshchera, 601501, Vladimir region, Gus-Hrustalnyi,

98 Internacionalnaya 111, Russian Federation, ${ }^{38}$ South Urals Federal Research Center of Mineralogy

99 and Geoecology of the Urals Branch of the Russian Academy of Sciences, Ilmeny State Reserve,

100 456317, Chelyabinskaya oblast, Miass, Russian Federation, ${ }^{39}$ FGBU National Park Kenozersky,

101 163000, Arkhangelsk, Embankment of the Northern Dvina, 78, Russian Federation, ${ }^{40}$ FGBU GPZ

102 Kologrivskij les im. M.G. Sinicina, 157440, Kostromskaja oblast', Kologriv, Nekrasova 48, Russian

103 Federation, ${ }^{41}$ Altai State University, 656049, Lenin Ave. 61, Barnaul, Russian

104 Federation, ${ }^{42}$ Pryazovskyi National Nature Park, 72312, Zaporiz'ka oblast, Melitopol', Interkulturna

105 Street, 21/1, Ukraine, ${ }^{43}$ State Nature Reserve Privolzhskaya Lesostep, 440031, Penza, Okruzhnaya

106 12-a, Russian Federation, ${ }^{44}$ Komarov Botanical Institute of the Russian Academy of Sciences (BIN

107 RAS), 197376, Saint Petersburg, Professora Popova 2, Russian Federation, ${ }^{45}$ Sary-Chelek State

108 Nature Reserve, 715705, Dzalal-Abad region, Aksu district, Arkyt village, Kyrgyzstan, ${ }^{46}$ Institute

109 for Evolutionary Ecology NAS Ukraine, 03143, Kiev, Lebedeva 37, Ukraine, ${ }^{47}$ FGBU State Nature

110 Reserve Kuznetsk Alatau, 652888, Kemerovo region, Mezhdurechensk, Shakhterov 33-1, Russian

111 Federation, ${ }^{48}$ Kerzhenskiy State Nature Biosphere Reserve, 603001, Nizhny Novgorod,

112 Rozhdestvenskaya 23, Russian Federation, ${ }^{49}$ FSBI United Administration of the Mordovia State

113 Nature Reserve and National Park Smolny, 430005, Republic of Mordovia, Saransk, Krasnaya 30,

114 Russian Federation, ${ }^{50}$ Ogarev Mordovia State University, 430005, Republic of Mordovia, Saransk,

115 Bolshevistskaya 68, Russian Federation, ${ }^{51}$ Bryansk Forest Nature Reserve, 242180, Bryansk region,

116 Suzemka district, Nerussa St., Zapovednaya street, 2, Russian Federation, ${ }^{52}$ Pinezhsky State Nature

117 Reserve, 164610, Arhangel region, Pinezkiy district, Pinega, Pervomayskaya street, 123 A, Russian

118 Federation, ${ }^{53}$ The Central Chernozem State Biosphere Nature Reserve named after Professor V.V.

119 Alyokhin, 305528 Kurskiy region, Kurskiy district, p/o Zapovednoe, Russian Federation, ${ }^{54}$ Tyumen

120 State University, 625043, Tyumen, Pirogova str., 3, Russian Federation, ${ }^{55}$ Reserves of Taimyr, 
666300, Norilsk, str. Talnakhskaya, entrance 2, Russian Federation, ${ }^{56}$ Chatkalski National Park, 100059, Toshkent, Shota Rustaveli St., 144-34, Uzbekistan, ${ }^{57}$ National Park Ugra, 248007, Kaluga, Prigorodnoe lesnichestvo, 3a, Russian Federation, ${ }^{58}$ Kaniv Nature Reserve, 19000, Kaniv, Shevchenko str. 108, Ukraine, ${ }^{59}$ Smolenskoe Poozerje National Park, 216270, Smolensk Region, Demidovskiy district, Przhevalskoe, Gurevitch street 19, Russian Federation, ${ }^{60}$ FSBI Zeya State Nature Reserve, 676246, Stroitelnaya str. 71, Zeya, Amurskaya Oblast, Russian Federation, ${ }^{61}$ Polistovsky State Nature Reserve, 182840, Pskov region, Bezhanitsy district, Bezhanitsy Sovetskaya street, 9B, Russian Federation, ${ }^{62}$ Ural State Pedagogical University, 620017, Yekaterinburg, prosp. Kosmonavtov, 26, Russian Federation, ${ }^{63}$ Institute of Mathematical Problems of Biology RAS - the Branch of the Keldysh Institute of Applied Mathematics of Russian Academy of Sciences, 142290, Moscow Region, Pushchino, Prof. Vitkevicha 1, Russian

Federation, ${ }^{64}$ Kronotsky Federal Nature Biosphere Reserve, 684000, Kamchatka region, Yelizovo, Ryabikova street 48, Russian Federation, ${ }^{65}$ Zhiguli Nature Reserve, 445362, Samara region, P. Bakhilova Polyana, Zhigulyovskaya 1, Russian Federation, ${ }^{66}$ Institute for Ecology and Geography, Siberian Federal University, 660041, Krasnoyarsk, 79 Svobodny pr., Russian Federation, ${ }^{67}$ Central Forest State Nature Biosphere Reserve, 172521, Tver region, Nelidovo district, Zapovedniy village, Russian Federation, ${ }^{68}$ National Park Bashkirija, 453870, Bashkortostan Republic, Meleuzovskiy district, Nurgush, Abubakirova 1, Russian Federation, ${ }^{69}$ State Nature Reserve Kurilsky, 694500, Sakhalin, Juzhno-Kurilsk, Zarechnaya 5, Russian Federation, ${ }^{70}$ Vodlozersky National Park, 185002 , Karelia, Petrozavodsk, Parkovaya 44, Russian Federation, ${ }^{71}$ State Nature Reserve Kivach, 186220, Kondopoga District, Republic of Karelia, Russian Federation, ${ }^{72}$ South-Ural Federal University, 4563304, Chelyabinskaya oblast, Miass, ul. Kalinina 37, Russian Federation, ${ }^{73}$ Saint-Petersburg State Forest Technical University, 194021, St. Petersburg, Institutsky per. 5, 1-338-3, Russian Federation, ${ }^{74}$ Astrakhan Biosphere Reserve, 414021, Astrakhan, Tsaerv River Bank 119, Russian 
145 Federation, ${ }^{75}$ FSBI United Administration of the Lazovsky State Reserve and national park Zov 146 Tigra, 692980, Primorskiy Krai, Lazovskiy District, Lazo, Centralnaya, 56, Russian

147 Federation, ${ }^{76}$ State Nature Reserve Tungusskiy, 660028, Krasnoyarsk region, Krasnoyarsk Street 27 148 19, Russian Federation, ${ }^{77}$ Krasnoyarsk State Pedagogical University named after V.P. Astafyev, 149 660049, Krasnoyarsk, Ada Lebedeva st. 89, Russian Federation, ${ }^{78}$ Institute of Geography, Russian 150 Academy of Sciences, 119017, Moscow, Staromonetniy 29, Russian Federation, ${ }^{79}$ Koltzov Institute 151 of Developmental Biology, Russian Academy of Sciences, 119334, Moscow, Vavilov Street 26, 152 Russian Federation, ${ }^{80}$ Carpathian National Nature Park, 78500, Ivano-Frankivsk region, Yaremche, 153 V. Stusa street 6, Ukraine, ${ }^{81}$ State Environmental Institution National Park Braslav lakes, 211970 , 154 Vitebsk region, Braslav, Dachnaya 1, Belarus, ${ }^{82}$ National Park Synevyr, 90041, Zakarpattia Region, 155 Mizhhirs'kyi district, Synevyr-Ostriki, Ukraine, ${ }^{83}$ Pasvik State Nature Reserve, 184421, Murmansk 156 region, Nikel, Gvardeyskiy Ave. 43, Russian Federation, ${ }^{84}$ Mari Chodra National Park, 425090, 157 Mari El Republic, Zvenigovsky District, Krasnogorsky Settlement, Tsentralnaya Street, 73, Russian 158 Federation, ${ }^{85}$ State Nature Reserve Vishersky, 618590, Perm region, Krasnovishersk, Gagarina 159 street 36B, Russian Federation, ${ }^{86}$ State Nature Reserve Olekminsky, 678100, Republic Sakha, 160 Olekminsk, Filatova 6, Russian Federation, ${ }^{87}$ Crimea Nature Reserve, 298514, Alushta, 161 Partizanskaya, 42, Republic of Crimea, ${ }^{88}$ Forest Research Institute Karelian Research Centre 162 Russian Academy of Sciences, 185910, Karelia, Petrozavodsk, Pushkinskaya 11, Russian 163 Federation, ${ }^{89}$ Black Sea Biosphere Reserve, 75600, Khersons'ka oblast, Hola Prystan', Mikhail 164 Lermontov 1, Ukraine, ${ }^{90}$ Institute of Physicochemical and Biological Problems in Soil Sciences 165 Russian Academy of Science, 142290, Moscow Region, Pushchino, Institutskaya 2, Russian 166 Federation, ${ }^{91}$ State Nature Reserve Nurgush, 610002, Kirov, Lenina street, 129a, Russian 167 Federation, ${ }^{92}$ Caucasian State Biosphere Reserve of the Ministry of Natural Resources, 385000, 168 Adygea Republik, Maykop, Sovetskaya str. 187, Russian Federation, ${ }^{93}$ National Nature Park 
169 Vyzhnytskiy, 59200, Chernivtsi Region, Vyzhnytsya District, Berehomet, Street Central 27 a,

170 Ukraine, ${ }^{94}$ National Park Khvalynsky, 412780, Region Saratov, Khvalynsk Sity, Oktyberskya

171 Street, 2b, Russian Federation, ${ }^{95}$ State Research Center Arctic and Antarctic Research Institute,

172 199397, Saint Petersburg, Bering st. 38, Russian Federation, ${ }^{96}$ Information-Analytical Centre for

173 Protected Areas, 123242, Moscow, Kapranova side-street 3, ${ }^{97}$ State Nature Reserve Malaya Sosva,

174 628242, Tjumen region, Sovetskiy, Lenina str., 46, Russian Federation, ${ }^{98}$ Krasnoyarsk State

175 Medical University named after Prof. V.F.Voino-Yasenetsky, 660022, Krasnoyarsk region,

176 Krasnoyarsk, Partizana Zhelezniaka, 1, Russian Federation, ${ }^{99}$ Surhanskiy State Nature Reserve,

177 191404, Surhandarja region, Sherabad, Agahi, 1, Uzbekistan, ${ }^{100}$ Mordovia State Nature Reserve,

178 431230, Mordovia Republic, Temnikov region, village Pushta, Russian Federation, ${ }^{101}$ Centre for

179 Biodiversity Dynamics, Department of Biology, Norwegian University of Science and Technology,

180 N-7491 Trondheim, Norway. ${ }^{102}$ Evgeniya Bukharova, Tatyana Gordeeva, Sergei Sazonov, Andrei

181 Sivkov, Viktor Teplov, and Vladimir Yakovlev are deceased.

182

$183 *$ Corresponding author: tomas.roslin@slu.se 
Ongoing climate change can shift organism phenology in ways that vary depending on species, habitats, and climate factors studied. To probe for large-scale patterns in associated phenological change, we use 70,709 observations from six decades of systematic monitoring across the former Soviet Union. Among 110 phenological events related to plants, birds, insects, amphibians and fungi, we find a mosaic of change, defying simple predictions of earlier springs, later falls and stronger changes at higher latitudes and elevations. Site mean temperature emerged as a strong predictor of local phenology, but the magnitude and direction of change varied with trophic level and the relative timing of an event. Beyond temperature-associated variation, we uncover high variation among both sites and years, with some sites being characterized by disproportionately long seasons and others by short ones. Our findings emphasize concerns regarding ecosystem integrity and highlight the difficulty of predicting climate change outcomes.

\section{Main text}

Climate change is restructuring biodiversity across the globe ${ }^{1}$. Among key responses to spatial and seasonal changes in ambient temperature are changes in phenology ${ }^{2,3}-$ i.e. changes in seasonrelated life cycle events. At mid- to high latitudes in the northern hemisphere, spring events are generally occurring earlier, whereas autumn events are occurring later, mostly due to rising temperatures ${ }^{2,4}$. Overall, responses are expected to be faster and more pronounced the higher the latitude or elevation, that is, the lower the average temperatures ${ }^{5-7}$.

Despite rough consensus regarding these general trends and expectations, there are substantial differences in the observed magnitude and direction of phenological responses to climate change among individual species ${ }^{8-10}$, different taxonomic groups and trophic levels ${ }^{3,11,12}$. Where spring 
phenology in terrestrial areas has advanced by a global average of 2.3 to 2.8 days/decade ${ }^{2,8,13}$, some studies have suggested changes as fast as 30 days per decade ${ }^{14}$. Higher rates of advance are possibly associated with lower trophic levels ${ }^{3,12}$, as perhaps reflecting not only different sensitivity to different drivers among trophic layers, but also different responses in terms of physiological development $^{3}$. Another factor which may accelerate phenological advance relates to the mean timing of an event within the season: spring-time events may be advancing at higher rates than autumn events ${ }^{15}$. On top of species-specific variation, there is also considerable site-specific variation in phenological advance ${ }^{16}$. Such variation among sites and populations may arise from a combination of factors, including changes in temperature and other climatic variables, population sizes, genetic differences, phenotypic plasticity, and land use ${ }^{16,17}$.

A general reason for variability in phenological responses is that patterns of climate change vary substantially across the globe. As the climate of different regions and biomes are changing in somewhat different ways ${ }^{5}$, uniform responses to climate change are hardly to be expected. Regional variation in climate change concern patterns in e.g. overall warming, precipitation and in the seasonal distribution of change ${ }^{6}$. Thus, changes in phenology can be expected to track local changes in the timing of abiotic or climatically-driven events, within the constraints set by the utilization of and sensitivity to cues of the regional species assemblage ${ }^{18-20}$. Such local and regional variation in drivers $^{19,21,22}$ and sensitivity towards them ${ }^{18,20}$ can be reflected in spatiotemporal variation in phenological shifts ${ }^{4,8,15,23,24}$. While the few studies analyzing geographically extensive datasets on phenology have observed spatial variation in temporal trends of phenological responses (e.g. ${ }^{25,26}$ ) and their main abiotic drivers ${ }^{5,27-29}$, the question remains whether patterns of change and response follow major environmental gradients in latitude, photoperiod or temperature ${ }^{15,16,30}$.

\section{Spatially extensive, long-term data across northern Eurasia}


231 Evaluating to what extent shifts in phenological events vary over space ${ }^{31}$, with their annual 232 timing ${ }^{3,11,12}$ or with trophic level ${ }^{16,32}$ requires consistently sampled, community-wide data which are 233 both long-term and spatially extensive $e^{3,12,16,32}$. Such data may also give insights on whether local 234 phenology is influenced by biotic interactions beyond abiotic cues ${ }^{7,33,34}$. Unfortunately, systematic 235 community-wide data sets are still uncommon, hampering progress in understanding large-scale 236 taxonomic and geographic patterns in phenological change ${ }^{35}$. The few existing exceptions (e.g. $2372,4,8,15,36,37$ ) are built on sparse data and/or combining individual studies using variable methods 238 (e.g. $\left.{ }^{38}\right)$. However, for such data, both noise and bias may affect the overall pattern detected. 239 Regarding seasonality, most datasets come with a particular bias, since much more interest has been 240 invested in spring- than in autumn-time events ${ }^{2,4,39}$. This is a problem, since where data are 241 available, phenological events occurring during different times of the year have oftentimes been 242 found to shift differently ${ }^{40}$.

243 Here, we draw on a uniquely comprehensive, long-term database established using uniform 244 protocols across northern Eurasia ${ }^{41-43}$. As this monitoring effort encompassed the timing of multiple 245 seasonal events as characterizing both climatic variation and a wealth of taxa (plants, birds, insects, 246 amphibians, reptiles and fungi; Fig. 1), it allows us to quantify large-scale patterns in phenological 247 responses over six decades. Specifically, we ask: 1) Has the timing of different phenological events 248 shifted similarly across this vast geographic range, measured in terms of the rate and direction 249 (advance or delay) of change?; 2) To what extent does variation in the rate and direction of change 250 follow major biogeographic gradients, such as latitude, photoperiod, temperature or chilling-degree251 days?; 3) To what extent can variation in the rate and direction of change be linked to the relative 252 seasonal timing of the event (early versus late), or to the species' trophic level?; and 4) To what 253 extent does variation in the timing of different events covary locally in ways not attributable to overall patterns, suggesting an effect of biotic interactions (and/or joint responses to unmeasured 
variables)? When combined, these questions allow us to characterize how different components of the ecosystem have shifted their phenologies over the last few decades of climate change, which environmental gradients can explain variation on a large spatial scale, and whether events occurring during different parts of the season or for different taxa keep pace with each other.

To quantify phenological shifts across events, trophic levels and environmental gradients, we fitted a joint species distribution model ${ }^{41}$ treating the dates of the phenological events as the multivariate response variable. To capture linear shifts in the timing of events, we included year as a fixed covariate, and to account for phenology varying with environmental or spatial gradients, we included the linear effect of four environmental descriptors of each study site (i.e., mean annual temperature, mean annual chilling sum, photoperiod, or latitude), with a separate model fitted for each descriptor (see below). Additionally, in order to quantify to what extent shifts in phenology differ along the environmental gradient, we included an interaction term between year and the environmental descriptor. Variation among sites beyond that explained by the environmental descriptor was captured by including site as a random factor, and similarly year-to-year variation beyond any linear trend was modelled by including year as a random factor. All events were grouped into abiotic ( $\mathrm{n}=28$; e.g. the transition of daily average temperatures above a given threshold, the melt of snow cover, or the breakup of ice on a given water body; Table S1) versus biotic events ( $n=82$; e.g. the first occurrence of a fungus species, the onset of blooming in a plant species, or the end of leaf fall for a tree species; Table S1), with the latter further split according to the species trophic level, yielding five "trophic levels" (producers, $n=54$; primary consumers, $n=4$; secondary consumers, $n=22$; and saprotrophs, $n=2$; Fig. 1; Table $S 1$ ). To evaluate how the multivariate response (i.e. dates of the phenological events) varies within year for each trophic level, we further included as explanatory variables the trophic level, the mean timing of the event across all sites, and their interaction. Since we treated the phenological events as the "species" of 
our joint species distribution model, we treated their characteristics (i.e. the trophic level or the mean timing of the event) as its "traits", just as one would model e.g. the body size or feeding guild of a species as its traits ${ }^{41,43}$. Thus, the explanatory variables were allowed to affect how the events respond to the fixed effects of year, the environmental descriptor (i.e., mean annual temperature, mean annual chilling sum, photoperiod, or latitude), and their interaction ${ }^{5,6,8}$. The periodic nature of seasons over time was captured by including the mean timing of the event as the linear effects of its cosine and sine transformations (see Methods for more details).

To examine the impact of different descriptors of climatic conditions at each site, we fitted four alternatives models to the data. Each model was identical in structure, but used an alternative climatic descriptor of the sampling sites. The specific metrics used were (1) the mean annual temperature in each study location, (2) the mean annual chilling sum (sum of degree days for those days for which the temperature is below zero), (3) the photoperiod (measured as the difference between the longest and shortest days of the year), and (4) the latitude of the site, with data sources for (1)-(3) identified in the Methods section. We fitted four separate models, rather than including all drivers into a single model, because all four drivers are highly correlated. Thus, their simultaneous inclusion in a single model would be of limited added value (in terms of variation "accounted for"), whereas it would compromise the interpretability of the results.

\section{How phenology is shifting across a continent}

All models provided adequate descriptions of the data, as evidenced by a high mean explanatory power: averaged over the events $\mathrm{R}^{2}$ was $74 \%$ for the model with latitude and $75 \%$ for all other models. We note that the reason why all models had similarly high explanatory power was that the part of the site-specific variation not explained by the climatic descriptor of the site was captured by the random effect of the site. The proportion of explained variation attributed to the climatic descriptor was $36 \%$ for the mean annual temperature of the site, $24 \%$ for the chilling sum, $27 \%$ for 
the photoperiod, and 28\% for the latitude (Extended Data Fig 2). Because mean annual temperature was the best predictor in the sense of explaining the most variation, we report the results of that model in the main text. All four models yielded qualitatively consistent results (Extended Data Figs. $1-8)$.

The explanatory power was greater for spring events than for autumn events, except for abiotic events (see Table S1) where it was consistently high (Fig. 2a for the model with mean temperature; Extended Data Figure 1 for other models). Averaged over the different events, $36.0 \%$ of the explained variance was attributed to the site mean temperature, $2.8 \%$ to the linear effect of year and its interaction with the temperature, $41.5 \%$ to the random effect of the site (i.e. variation among sites not explained by mean temperature), $13.4 \%$ to the random effect of the year (i.e. variation among years not explained by linear trends), and $6.4 \%$ to the random effect of the sample (i.e. synchronous variation at the level of site-year combinations; Fig. 2b).

Spring events tend to occur earlier and autumn events tend to occur later at warmer (typically lower latitude or elevation) sites, creating a longer activity period or growing season, as reflected by a strong negative effect of temperature on spring event timing and strong positive effect for autumn event timing (Fig. 3a, b). For a large proportion (54\%) of all events, we found strong statistical support (at least $95 \%$ posterior probability) for a shift towards an earlier date, whereas fewer events (10\%) showed strong statistical support for a shift towards a later date (Fig. 3a). As examples of events shifting towards an earlier date, we find the break of ice cover, the first blooming of many plants (from Tussilago, Tussilago farfara, to the Lily of the valley, Convallaria majalis), the first flight of bumblebees, Bombus, and the first occurrence of a range of bird species (ranging from the swift Apus apus to the crane Grus grus). Among events shifting towards a later date, we find the formation of snow and ice cover, the timing of autumn colours and leaf fall in several trees (from aspen Populus tremula to birch Betula pendula), and - perhaps oddly enough - the spring-time 
awakening of the brown bear, Ursus arctos. Specifically, spring events showed the strongest shift towards earlier dates, whereas autumn events showed the strongest shifts towards later dates (Fig. 3c). This was particularly evident for primary producers, which overall showed stronger shifts in both directions; i.e. plants advanced early or delayed late events faster than did higher trophic levels. By comparison, the abiotic events showed even stronger shifts in both directions for both temperature and year effects. Thus, abiotic change, consumers and producers slide apart as springs shift earlier and autumns later.

Additionally, shifts were more positive at warmer sites for some events (18\% showed strong statistical support; Fig. 3d), but more negative for others (15\%; Fig. 3d), with no clear pattern over time or across trophic levels. Among those events that showed a strong statistical support for an overall shift to earlier, $17 \%$ showed a strong statistical support for shifting to earlier especially in cold sites and $16 \%$ in warm sites (Fig. 3e). Among those events that showed a strong statistical support for an overall shift to later, $11 \%$ showed a strong statistical support for shifting to later especially in cold sites and $22 \%$ in warm sites (Fig. 3e). As concrete examples of events which have actually shifted later at cold sites but earlier at warm sites, we find the first spring rain, the onset of blooming in Scots pine (Pinus sylvestris) and Marsh Labrador tea (Rhododendron tomentosum, syn. Ledum palustre), and the first song of the skylark (Alauda arvensis). Among events shifting earlier at cold sites but later at warm sites, we find e.g. the arrival of the rook (Corvus frugilegus), and the ripening of blueberry (Vaccinium myrtillus) and lingonberry (Vaccinium vitis-idaea).

The random effect of site was positively associated both within spring and within autumn events, but negatively associated between spring and autumn events (Fig. 4a); i.e., at any given site, spring events tended to occur particularly early while all autumn events particularly late, or vice versa, after accounting for the effect of site mean temperature. This pattern remained qualitatively unchanged when replacing mean temperature with other environmental descriptors (mean chilling 
sums, photoperiod or latitude; see Extended Data Fig. 6). Thus, summer - in the sense of the biologically active period - tends to be particularly long at some sites and particularly short at other sites, a pattern which is only partly captured by simple environmental gradients (for potential explanations, see below). The random effect of year was positively correlated among events overall, but especially among spring events, meaning that some years are characterized by early spring phenology and others by late spring phenology across all events and trophic levels (Fig. 4b). Perhaps most interestingly, though, the random effect at the level of the sampling unit (i.e. the siteby-year combination) showed positive association among most phenological events. Thus, a large majority of all phenological events within a given site in a given year tended to be consistently "early" or "late" to an extent unexplicable by the effect of the year as such (Fig. 4c) - a pattern suggesting that some other factor may be orchestrating the relative timing of events at the level of the local community.

\section{Striking variation over space, species and trophic levels}

Our results highlight considerable spatial, seasonal and trophic heterogeneity in the magnitude and direction of shifts in phenological timing. While much of the large-scale variation can be attributed to a simple environmental gradient, phenological responses to ongoing climate change can idiosyncratically cause advance or delay over time within regions, and among sites and trophic levels. The strong effect of site beyond the effect of mean temperature (as shown by the overall partitioning of variance in our model; Figs. 2 and Extended Data Fig. 2) importantly qualifies the expectation of a strong and general pattern of phenology change along latitudinal or other environmental gradients ${ }^{17}$. Yet, it is consistent with our previous work ${ }^{17}$ showing that phenological plasticity is constrained by local differentiation in reaction norms to temperature $\operatorname{cues}^{44}$, i.e., by local adaptation (see also ${ }^{18,45}$ ). Under such a scenario, we would indeed expect site-specific variation in phenology beyond patterns attributable to average temperature or its change over time. 
However, it is worth noting that different abiotic events (such as snowmelt, ice formation and ice break) likewise vary differently with mean temperature, change differently over time, and remain cross-correlated even when temperature has been accounted for (Figs. 3, 4). In other words, early sites tend to remain early, and late sites tend to remain late, both with respect to the biotic and abiotic components of the local ecosystems. Most interestingly, the overall timing of events tends to be more synchronized than suggested by the overall effect of year. The strong dominance of positive residual associations between event-pairs at the random sample level (Figs. 4c and Extended Data Fig. 8) implies that an early date of one given event is associated with an earlier date in another beyond the advance expected by the overall earliness of the year. Residual covariance at this level could potentially be interpreted as a sign of a synchronizing effect of biotic interactions among species. In doing so, we should naturally exercise the same caution as whenever statistically observed associations are interpreted as biotic interactions ${ }^{41,43}$. It is also worth noting that beyond biotic interactions, this result is likely to partly reflect the synchronizing effect of abiotic conditions which affect multiple events, as well as the fact that different phenophases within one and the same species are interconnected with each other (e.g a migratory bird species cannot breed without first arriving, so the timing of breeding is constrained by the timing of arriving). Regarding the latter type of dependencies, we note that while we scored two or more separate phenological events in several species (Supplementary Information, Table S1), such repeated measures concerned far too few species to account for the vast predominance of positive residual associations observed overall. Thus, the pattern observed may be seen as suggestive, but clearly inconclusive of evidence for an imprint of biotic interactions on community-level phenology $y^{7,33,34}$.

Overall, strong phenological shifts over time occur not in lieu of but on top of the imprints of environmental gradients of mean temperature, photoperiod and latitude ${ }^{5,6,8}$. That is, strong added imprints of site on local phenology change might stem from spatial variation in additional factors 
varying more idiosyncratically in space, rather than as smooth gradients. Species respond to multiple climatic dimensions over time $e^{46,47}$, and the effects of climate on phenology may further vary with habitat ${ }^{48}$, urbanization ${ }^{49,50}$, and precipitation ${ }^{5,6}$. Thus, an anthropogenic-induced shift in the macroclimate ${ }^{4,5,15,32}$, potentially leading to large-scale environmental changes along latitudes ${ }^{51}$ or other geographical gradients, may be further modified by the local changes that species are responding to customized by the local conditions that they have adapted to. Such added impacts could limit the scope for space-for-time substitutions ${ }^{16}$, and leads us to warn against uncritical extrapolation of trends observed among sites, trophic levels, or from one region to another ${ }^{5}$.

As proposed by Burrows et al. ${ }^{17,52}$, the observed patterns of shifts in phenology should be compared to patterns in the velocity and seasonal shift of climate change. In this context, we note that our current data include both abiotic climate-related events and biotic responses, with the former shifting more than the latter. These disparities between the rates of change in the abiotic environment and species responses match previous observations that current phenological plasticity is not keeping pace with variation in climatic conditions ${ }^{3,17,18,22,53-56}$. Mismatches between the velocity of climate change and realised seasonal shifts may help identify regions of concern, e.g. where phenology change is lagging behind species thermal niches.

\section{Ecosystem integrity imperilled yet understudied}

Our findings emphasize concerns regarding ecosystem integrity, as the velocity of change in space and time differed between interacting trophic levels. Combined with different responses among events over different parts of the season, this variation can lead to temporal mismatches between species ${ }^{1,11,56}$ and potentially affect community structure and persistence. Importantly, a shift in the timing of an event related to one life-stage may propagate to another, but our current dataset holds limited resolution towards resolving such knock-on effects. To establish whether the stability and persistence of natural systems is ultimately affected by the loss of phenological synchrony at one 
stage, or within food webs, we need a much-improved understanding of the interplay between spatial, trophic, species- and event-specific patterns in phenological responses (e.g. ${ }^{35}$ ).

Accumulated negative effects of rapid seasonal shifts across many species may threaten biodiversity ${ }^{14,57,58}$. Surprisingly enough, our current findings suggest that phenological shifts during the last few decades may differ between warmer and colder locations across our study area. In this context, we stress that our estimates concern absolute, not relative, rates of change. Counterweighing the interpretation of stronger shifts at warmer (thus more southern or lower elevations) sites is the fact that phenology is naturally constrained by the overall length of the season. At high latitudes, i.e. in colder regions, a shift of a few days may amount to a considerable part of the full growing season. As polar areas warm at faster rates, resident organisms might lose major parts of their phenological niches ${ }^{21}$. In contrast, areas of slower seasonal shifts, and smaller relative shifts, may be important repositories for both biodiversity and ecosystem integrity ${ }^{5}$. Our current study provides a first attempt in this direction, and will hopefully inspire more work to come.

\section{References}

1. Pecl, G. T. et al. Biodiversity redistribution under climate change: Impacts on ecosystems and human well-being. Science 355, eaai9214- (2017).

2. Parmesan, C., Yohe, G. \& Andrus, J. E. A globally coherent fingerprint of climate change impacts across natural systems. Nature 421, 37-42 (2003).

3. Thackeray, S. J. et al. Trophic level asynchrony in rates of phenological change for marine, freshwater and terrestrial environments. Global Change Biology 16, 3304-3313 (2010).

4. Root, T. L. et al. Fingerprints of global warming on wild animals and plants. Nature 421, 57-60 (2003).

5. Burrows, M. T. et al. The pace of shifting climate in marine and terrestrial ecosystems. Science 334, 652-655 (2011).

6. IPCC. Climate Change 2013: The Physical Science Basis. Contribution of Working Group I to the Fifth Assessment Report of the Intergovernmental Panel on Climate Change. (Cambridge University Press, 2013). 
7. Pau, S. et al. Predicting phenology by integrating ecology, evolution and climate science. Global Change Biology 17, 3633-3643 (2011).

8. Parmesan, C. Influences of species, latitudes and methodologies on estimates of phenological response to global warming. Global Change Biology 13, 1860-1872 (2007).

9. Both, C., van Asch, M., Bijlsma, R. G., van den Burg, A. B. \& Visser, M. E. Climate change and unequal phenological changes across four trophic levels: Constraints or adaptations? Journal of Animal Ecology 78, 73-83 (2009).

10. Cook, B. I., Wolkovich, E. M. \& Parmesan, C. Divergent responses to spring and winter warming drive community level flowering trends. Proceedings of the National Academy of Sciences of the United States of America 109, 9000-9005 (2012).

11. Voigt, W. et al. Trophic levels are differentially sensitive to climate. Ecology 84, 2444-2453 (2003).

12. Thackeray, S. J. et al. Phenological sensitivity to climate across taxa and trophic levels. Nature 535, 241-245 (2016).

13. Cohen, J. M., Lajeunesse, M. J. \& Rohr, J. R. A global synthesis of animal phenological responses to climate change. Nature Climate Change 8, 224-228 (2018).

14. Høye, T. T., Post, E., Meltofte, H., Schmidt, N. M. \& Forchhammer, M. C. Rapid advancement of spring in the High Arctic. Current Biology 17, R449-R451 (2007).

15. Menzel, A., Sparks, T. H., Estrella, N. \& Roy, D. B. Altered geographic and temporal variability in phenology in response to climate change. Global Ecology and Biogeography 15, 498-504 (2006).

16. Primack, R. B. et al. Spatial and interspecific variability in phenological responses to warming temperatures. Biological Conservation 142, 2569-2577 (2009).

17. Delgado, M. M. et al. Differences in spatial versus temporal reaction norms for spring and autumn phenological events. Proceedings of the National Academy of Sciences of the United States of America Accepted, (2020).

18. Renner, S. S. \& Zohner, C. M. Climate change and phenological mismatch in trophic interactions among plants, insects, and vertebrates. Annual Review of Ecology and Systematics 49, 165-182 (2018).

19. Ackerly, D. D. et al. The geography of climate change: Implications for conservation biogeography. Diversity and Distributions 16, 476-487 (2010).

20. Zohner, C. M., Benito, B. M., Fridley, J. D., Svenning, J. C. \& Renner, S. S. Spring predictability explains different leaf-out strategies in the woody floras of North America, Europe and East Asia. Ecology Letters vol. 20 452-460 (2017).

21. Loarie, S. R. et al. The velocity of climate change. Nature 462, 1052-1055 (2009).

22. Visser, M. E. \& Both, C. Shifts in phenology due to global climate change: The need for a yardstick. Proceedings of the Royal Society B: Biological Sciences 272, 2561-2569 (2005).

23. Hurlbert, A. H. \& Liang, Z. Spatiotemporal variation in avian migration phenology: Citizen science reveals effects of climate change. PLOS ONE 7, e31662- (2012). 
24. Rubolini, D., Møller, A. P., Rainio, K. \& Lehikoinen, E. Intraspecific consistency and geographic variability in temporal trends of spring migration phenology among European bird species. Climate Research 35, 135-146 (2007).

25. Cohen, J. M., Lajeunesse, M. J. \& Rohr, J. R. A global synthesis of animal phenological responses to climate change. Nature Climate Change 8, 224-228 (2018).

26. Geng, X. et al. Climate warming increases spring phenological differences among temperate trees. Global Change Biology doi.org/10.1111/GCB.15301- (2020) doi:10.1111/gcb.15301.

27. Both, C. et al. Large-scale geographical variation confirms that climate change causes birds to lay earlier. Proceedings of the Royal Society B: Biological Sciences 271, 1657-1662 (2004).

28. Menzel, A. \& Fabian, P. Growing season extended in Europe. Nature 397, 659- (1999).

29. Körner, C. \& Basler, D. Phenology under global warming. Science 327, 1461-1462 (2010).

30. Flynn, D. F. B. \& Wolkovich, E. M. Temperature and photoperiod drive spring phenology across all species in a temperate forest community. New Phytologist 219, 1353-1362 (2018).

31. Ovaskainen, O. et al. Community-level phenological response to climate change. Proceedings of the National Academy of Sciences of the United States of America 110, 13434-13439 (2013).

32. Doi, H. \& Takahashi, M. Latitudinal patterns in the phenological responses of leaf colouring and leaf fall to climate change in Japan. Global Ecology and Biogeography 17, 556-561 (2008).

33. Elzinga, J. A. et al. Time after time: flowering phenology and biotic interactions. Trends in Ecology and Evolution vol. 22 432-439 (2007).

34. Vilela, A. A., del Claro, V. T. S., Torezan-Silingardi, H. M. \& Del-Claro, K. Climate changes affecting biotic interactions, phenology, and reproductive success in a savanna community over a 10-year period. Arthropod-Plant Interactions 12, 215-227 (2018).

35. Kharouba, H. M. \& Wolkovich, E. M. Disconnects between ecological theory and data in phenological mismatch research. Nature Climate Change vol. 10 406-415 (2020).

36. Walther, G.-R. et al. Ecological responses to recent climate change. Nature 416, 389-395 (2002).

37. Ge, Q., Wang, H., Rutishauser, T. \& Dai, J. Phenological response to climate change in China: A metaanalysis. Global Change Biology 21, 265-274 (2015).

38. Gallinat, A. S., Primack, R. B. \& Wagner, D. L. Autumn, the neglected season in climate change research. Trends in Ecology and Evolution 30, 169-176 (2015).

39. Menzel, A. et al. European phenological response to climate change matches the warming pattern. Global Change Biology 12, 1969-1976 (2006).

40. Ovaskainen, O. et al. Chronicles of nature calendar, a long-term and large-scale multitaxon database on phenology. Scientific Data 7, 47- (2020).

41. Ovaskainen, O. et al. How to make more out of community data? A conceptual framework and its implementation as models and software. Ecology Letters 20, 561-576 (2017). 
42. Tikhonov, G. et al. Joint species distribution modelling with the R-package HMSC. Methods in Ecology and Evolution 11, 442-447 (2019).

43. Ovaskainen, O. \& Abrego, N. Joint Species Distribution Modelling With Applications in R. ( Cambridge University Press, 2020).

44. Phillimore, A. B., Hadfield, J. D., Jones, O. R. \& Smithers, R. J. Differences in spawning date between populations of common frog reveal local adaptation. Proceedings of the National Academy of Sciences of the United States of America 107, 8292-8297 (2010).

45. Garcia, R. A., Cabeza, M., Rahbek, C. \& Araújo, M. B. Multiple dimensions of climate change and their implications for biodiversity. Science 344, 1247579-1 (2014).

46. Kudo, G. \& Hirao, A. S. Habitat-specific responses in the flowering phenology and seed set of alpine plants to climate variation: Implications for global-change impacts. Population Ecology 48, 49-58 (2006).

47. Altermatt, F. Temperature-related shifts in butterfly phenology depend on the habitat. Global Change Biology 18, 2429-2438 (2012).

48. Neil, K. \& Wu, J. Effects of urbanization on plant flowering phenology: A review. Urban Ecosystems 9, 243-257 (2006).

49. Shen, M., Piao, S., Cong, N., Zhang, G. \& Jassens, I. A. Precipitation impacts on vegetation spring phenology on the Tibetan Plateau. Global Change Biology 21, 3647-3656 (2015).

50. Zhang, J. et al. Rapid shifts of peak flowering phenology in 12 species under the effects of extreme climate events in Macao. Scientific Reports 8, 13950- (2018).

51. Chuine, I. Why does phenology drive species distribution? Philosophical Transactions of the Royal Society B: Biological Sciences 365, 3149-3160 (2010).

52. Radchuk, V. et al. Adaptive responses of animals to climate change are most likely insufficient. Nature Communications 10, 3109- (2019).

53. Harrington, R., Woiwod, I. \& Sparks, T. Climate change and trophic interactions. Trends in Ecology \& Evolution 14, 146-150 (1999).

54. Carter, S. K., Saenz, D. \& Rudolf, V. H. W. Shifts in phenological distributions reshape interaction potential in natural communities. Ecology Letters 21, 1143-1151 (2018).

55. Rudolf, V. H. W. The role of seasonal timing and phenological shifts for species coexistence. Ecology Letters 22, 1324-1338 (2019).

56. Kharouba, H. M. et al. Global shifts in the phenological synchrony of species interactions over recent decades. Proceedings of the National Academy of Sciences of the United States of America 115, 5211-5216 (2018).

57. Høye, T. T., Post, E., Schmidt, N. M., Trøjelsgaard, K. \& Forchhammer, M. C. Shorter flowering seasons and declining abundance of flower visitors in a warmer Arctic. Nature Climate Change 3, 759-763 (2013). 
58. Schmidt, N. M. et al. An ecological function in crisis? The temporal overlap between plant flowering and pollinator function shrinks as the Arctic warms. Ecography 39, 1250-1252 (2016).

\section{Methods}

We used data from Ovaskainen et al. ${ }^{59}$, who compiled dates of phenological events (for concrete examples, see Supplementary Information, Table T1.1) systematically recorded for multiple taxonomic groups in 471 localities across the Russian Federation, Ukraine, Uzbekistan, Belarus and Kyrgyzstan. In addition, the database includes dates on climatic events recorded at each locality (e.g., ice formation and first day of snowfall). The data were curated by EarthCape ${ }^{60}$ and published on Zenodo ${ }^{59}$. From this set, we selected events for which there were at least 100 data points in total, and at least 10 data points from at least 10 sites. Further, we only included sites that were at least 25 $\mathrm{km}$ apart, and sampling units for which there were at least 10 events recorded. All anthropogenic events, such as dates for sowing and harvest, were excluded from this analysis. This process yielded 70,709 phenological observations for 110 events across 113 locations (Fig. 1). The data included 52 taxa and four types of meteorological events (Supplementary Info, Table S1.1), and covered the period between 1960-2017 (earlier records were excluded), spanning $43.08^{\circ}-67.82^{\circ}$ latitude and $21.15^{\circ}-136.15^{\circ}$ longitude.

The sampling units consist of (site, year) pairs. We denote by $y_{i j}$ the date on which the phenological event $j$ took place in sampling unit $i$. These are combined in the data matrix $\mathbf{Y}=\left\{y_{i j}\right\}$ with $j=1, \ldots, n_{s}=110$ events recorded in $i=1, \ldots, n_{y}=2789$ sampling units. The data consist of 70,709 dates, so that $77 \%$ of the entries in the $\mathbf{Y}$ matrix are missing (NA) due to not all events being recorded in all sites and in all years. To these data, we fitted Hierarchical Modeling of Species Communities (HMSC) models ${ }^{41,43}$. HMSC is a multivariate Bayesian generalized linear mixed modelling framework, which allowed us to account for both correlation among the 
phenological events included in the models, as well as for the spatio-temporal structure of the study $\operatorname{design}^{41-43}$. Additionally, HMSC allows including trait information to inform species-level responses to model covariates ${ }^{41}$ - in our case, event-level responses. Here, we summarize our rationale and inference, while an in-depth description of the HMSC model fitted is provided in Supplementary Information, Text S2.

As predictors related to each sampling unit $i$, we included the linear effect of year of the sampling, aimed to capture temporal shifts in phenology which are the main focus of this study. To account for phenological variation due to climatic conditions, as well as to capture any systematic variation in the phenological shifts as a function of climatic conditions, we also included a variable describing the overall (not year-specific) climatic conditions at each study site, and its interaction with the linear effect of year. As climatic descriptor, we considered four alternatives variables based on ${ }^{29}$, who identified the three most important factors controlling phenology in primary producers as the degree of winter chilling, photoperiod (day length relative to night length), and temperature. We thus derived descriptors of spatial variation in each of these three variables, and showed that our main results were upheld across each (Extended Data Figs. 1-8). Specifically, these were (1) the mean annual temperature, (2) the mean annual chilling sum (calculated as the sum of degree days for those days for which the temperature is below zero), and (3) the photoperiod measured as the difference between the longest and shortest days of the year, for each site. In addition, we considered (4) the absolute latitude of the site, as a standard descriptor of space as such in both phenological $^{61}$ and other biogeographic analyses ${ }^{62}$. We note that photoperiod is a function of latitude, but that the two are non-linearly related to each other. For this reason, we included latitude per se as a separate, potential climatic descriptor. To compute the mean annual temperature and the mean annual chilling sum, we used the ERA5-Land data (representing the period 1979-2019) ${ }^{63,64}$. To calculate the photoperiod, we used the daylength function of the R-package geosphere ${ }^{65}$. 
607 To examine how the shifts and their dependency on the climatic conditions co-varied among different types of phenological events, we also included event-level predictors (i.e., species traits in the HMSC framework): (1) the mean timing of each event (calculated as the mean day of the year over the entire data set); and (2) the trophic level of the species for which the phenological event was recorded (classified as producers, primary consumers, secondary consumers, and saprotophs, or abiotic events). To account for the periodic nature of seasons over time, we included the mean timing of each event as the linear effect of its cosine and sine transformations. To account for the nature of the study design and to evaluate co-variation among the phenological events, we included three random effects for the site, the year, and the sampling unit (i.e. year-site pairs). All of these were modelled at the community-level, using the latent variable approach of $\mathrm{HMSC}^{41,43}$. This allowed us to assess the relationships among phenological events that could not be explained by responses to the main covariates, and for each of the three random effect levels included in our models. For a more technical description of the HMSC model, we refer the reader to ${ }^{41-43}$.

We fitted the models with package $\mathrm{Hmsc}^{42}$ in $\mathrm{R}^{66}$ assuming the default prior distributions (see ${ }^{42,43}$ ). We performed posterior sampling for four Markov Chain Monte Carlo (MCMC) chains, each of which we sampled for 375,000 iterations, out of which we discarded the first 125,000 as a transient and thinned the remaining by 1000 , thus yielding 250 samples per chain and 1000 samples in total. To evaluate MCMC convergence, we examined the distributions of the potential scale reduction factor over the parameters related to the fixed effects ( $\beta$-parameters) and the random effects ( $\Omega$ parameters), equivalent to the Gelman-Rubin statistic ${ }^{67}$.

Overall, we note that our aim is to quantify spatial variation in the rates (slope) of phenological change over time, not to identify the specific drivers of the timing of each individual event. To emphasize this point, we stress that we regressed phenological timing on year and on descriptors of each site's position in physical (latitude) or environmental space (average temperature, average sum 
631 of chilling degree days or photoperiod), not on year-to-year variation in some specific driver. What

632

633

634 635

636

637

638

639

640

641

642

643

644

645

646

647

648

649

650

651

652

653

our analyses show is thus that trophic level and seasonal timing of an event affect how it has shifted over time, and that the rate of shift is further affected by its position along the biogeographic gradient, whereas the exact descriptor of this gradient has little impact on the results (Extended Data Figs. 1-8).

\section{Reporting summary}

Reporting summary. Further information on research design is available in Nature Research Reporting Summary linked to this article.

\section{Data availability}

The data that support the findings of this study are available in ${ }^{40,59}$, with the exact subset of the data used in the present analyses available at https://doi.org/10.5281/zenodo.3774386.

\section{Code availability}

The code needed to replicate the current analyses, from data extraction to parameter estimates presented, is available at https://doi.org/10.5281/zenodo.3774386.

\section{References}

59. Ovaskainen, O. et al. Chronicles of Nature Calendar, a long-term and large-scale multitaxon database on phenology. Zenodo https://doi.org/10.5281/zenodo.3607556- (2020).

60. Meyke, E. When data management meets project management. Biodiversity Information Science and Standards 3, e37224- (2019). 
61. Chmura, H. E. et al. The mechanisms of phenology: the patterns and processes of phenological shifts. Ecological Monographs vol. 89 (2019).

62. Willig, M. R. \& Presley, S. J. Latitudinal gradients of biodiversity: Theory and Empirical Patterns. in Encyclopedia of the Anthropocene vol. 3 13-19 (Elsevier, 2017).

63. Copernicus Climate Change Service (C3S) (2019): C3S ERA5-Land reanalysis . Copernicus Climate Change Service, accessed July 12, 2020. https://cds.climate.copernicus.eu/cdsapp\#!/home.

64. Hersbach, H. et al. The ERA5 global reanalysis. Quarterly Journal of the Royal Meteorological Society (2020) doi:10.1002/qj.3803.

65. Hijmans, R. J., Williams, E. \& Vennes, C. geosphere: Spherical Trigonometry. R package version 1.5-10. (2019).

66. R Core Team. R: A language and environment for statistical computing. (R Foundation for Statistical Computing, 2018).

67. Gelman, A. et al. Bayesian Data Analysis. (2013).

\section{Acknowledgements}

The field work was conducted as part of the monitoring program of nature reserves, Chronicles of

Nature. The work was financially supported by the Academy of Finland, grants 250243 (OO),

284601 (OO), 309581 (OO); the European Research Council, ERC Starting Grant 205905 (OO) and

Synergy Grant 856506 — LIFEPLAN (to OO and TR); Nordic Environment Finance Corporation

Grant (OO); Jane and Aatos Erkko Foundation Grant (OO, TR, MH, LA); University of Helsinki

HiLIFE Fellow Grant 2017-2020 (OO); and the Research Council of Norway through its Centres of

Excellence Funding Scheme (223257) to OO via Centre for Biodiversity Dynamics; the Kone

Foundation 44-6977 (MD) and 55-14839 (GT); a Spanish Ramon y Cajal grant RYC-2014-16263

(MD); the Federal Budget for the Forest Research Institute of Karelian Research Centre Russian

Academy of Sciences 220-2017-0003, 0220-2017-0005 (LV, SS and JK); the Russian Foundation

for Basic Research Grant 16-08-00510 (LK), and the Ministry of Education and Science of the

Russian Federation 0017-2019-0009 (Keldysh Institute of Applied Mathematics, Russian Academy 
682 of Sciences) (NI, MSh). The authors wish to extend their particular thanks to additional colleagues

683 contributing to data collection, especially A. Beshkarev, G. Bushmakova, T. Butorina, L. Chrevova, 684 A. Esipov, N. Gordienko, E. Kireeva, V. Koltsova, I. Kurakina, V. Likhvar, I. Likhvar, D.

685 Mirsaitov, M. Nanynets, L. Ovcharenko, L. Rassohina, E. Romanova, A. Shelekhov, N. Shirshova, 686 D. Sizhko, I. Sorokin, H. Subota, V. Syzhko, G. Talanova, P. Valizer and A. Zakusov.

687

688 Author Contributions

689 The data were collected by the 195 authors starting from Marina Abadonova and ending with 690 Tatyana Zubina in the author list. Juri Kurhinen, Evgeniy Meyke, Coong Lo, Gleb Tikhonov and 691 Eliezer Gurarie contributed to the establishment and coordination of the collaborative network and 692 to the compilation and curation of the resulting dataset. Tomas Roslin, Otso Ovaskainen, Laura 693 Antão, Maria Hällfors, and Maria del Mar Delgado conceived of the idea behind the current study 694 and wrote the first draft of the paper, with Otso Ovaskainen conducting the analyses. All authors 695 provided useful comments on earlier drafts.

696

697 Competing Interests

698 The authors declare no competing interests.

699 


\section{Number of data points over time}
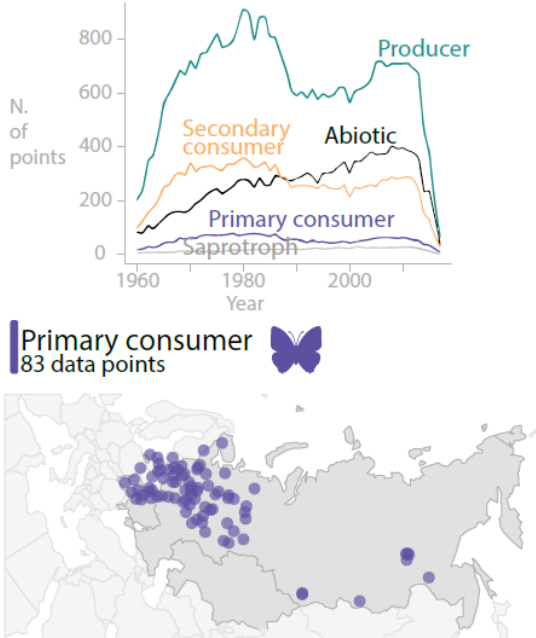

Abiotic events

31 data points

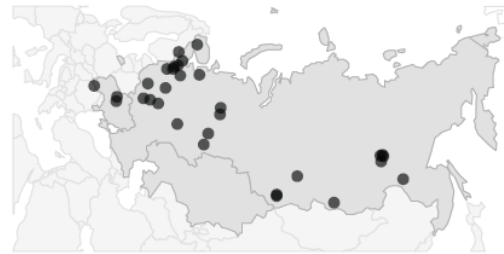

Secondary consumer 91 data points
| Producer

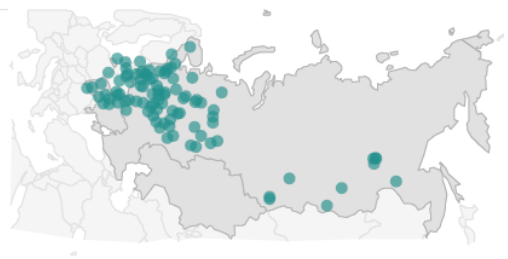

Saprotrophs

\section{Mean temperature ${ }^{\circ} \mathrm{C}$}

\section{$\begin{array}{ll}-7 & -6\end{array}$}

$\begin{array}{lll}1 & -5 & -2\end{array}$

(1) -13

(1) 45

- 67

Figure 1. Illustration of the study design and the extent of data. Individual panels show top-left: provenance of data of each type; and bottom: mean annual temperature for each sampling location. All events were classified into four trophic levels according to the organism expressing the event: primary producers (plants), primary consumers (herbivorous insects), secondary consumers the remains of multiple other levels). 

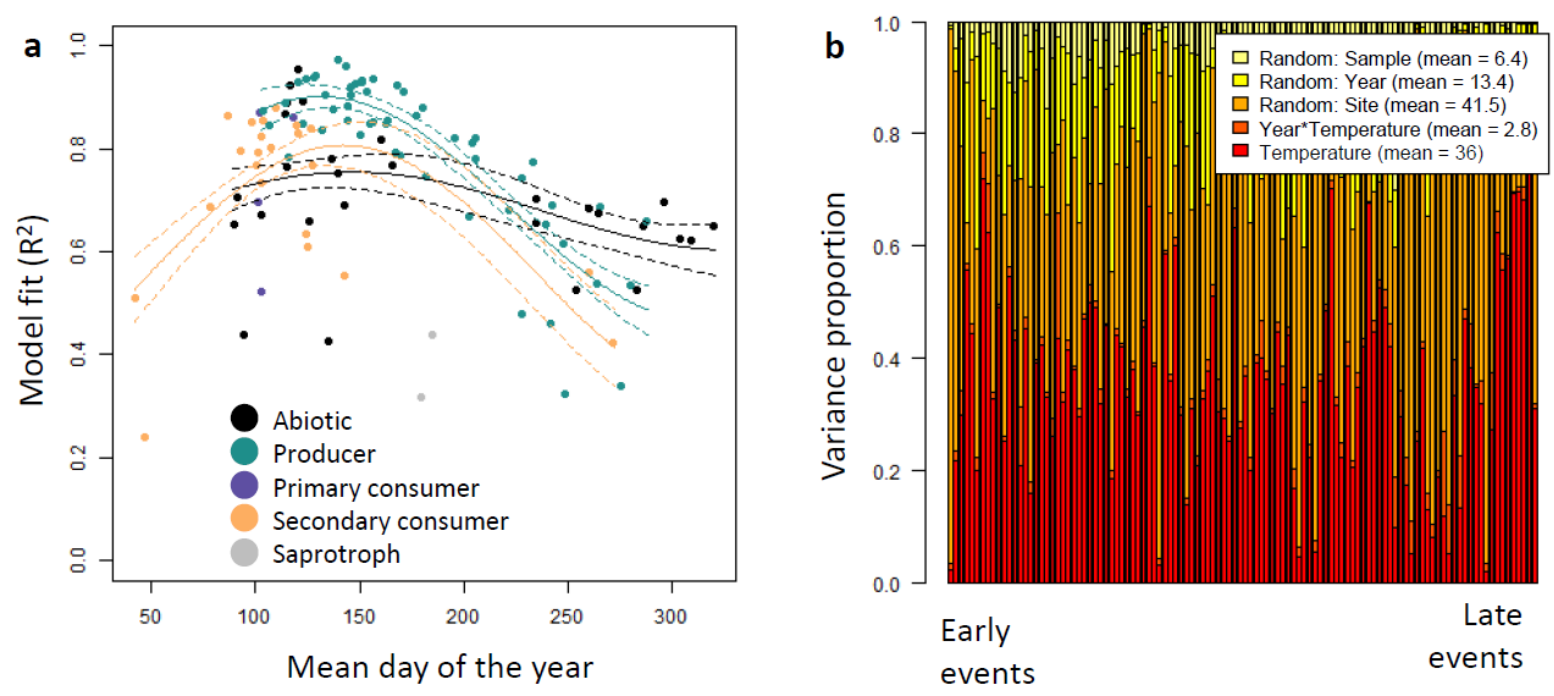

711 Figure 2. Explanatory power (a) and variance partitioning (b) of the HMSC-model with mean 712 annual temperature as explanatory variable. a, Degree of determination $\left(R^{2}\right)$ as a function of the 713 timing of the event (mean day of the year when the event occurs) and of the trophic level of the 714 organism expressing the event (shown by curves in different colours). Here, curves show second715 order models fitted to groups with at least 5 events; continuous lines show mean model prediction 716 and dashed lines \pm 1 standard error. $\mathbf{b}$, Partitioning of the overall variance of the data into the 717 different model components. Here, individual events have been sorted from the earliest to the latest 718 (left to right along abscissa). 

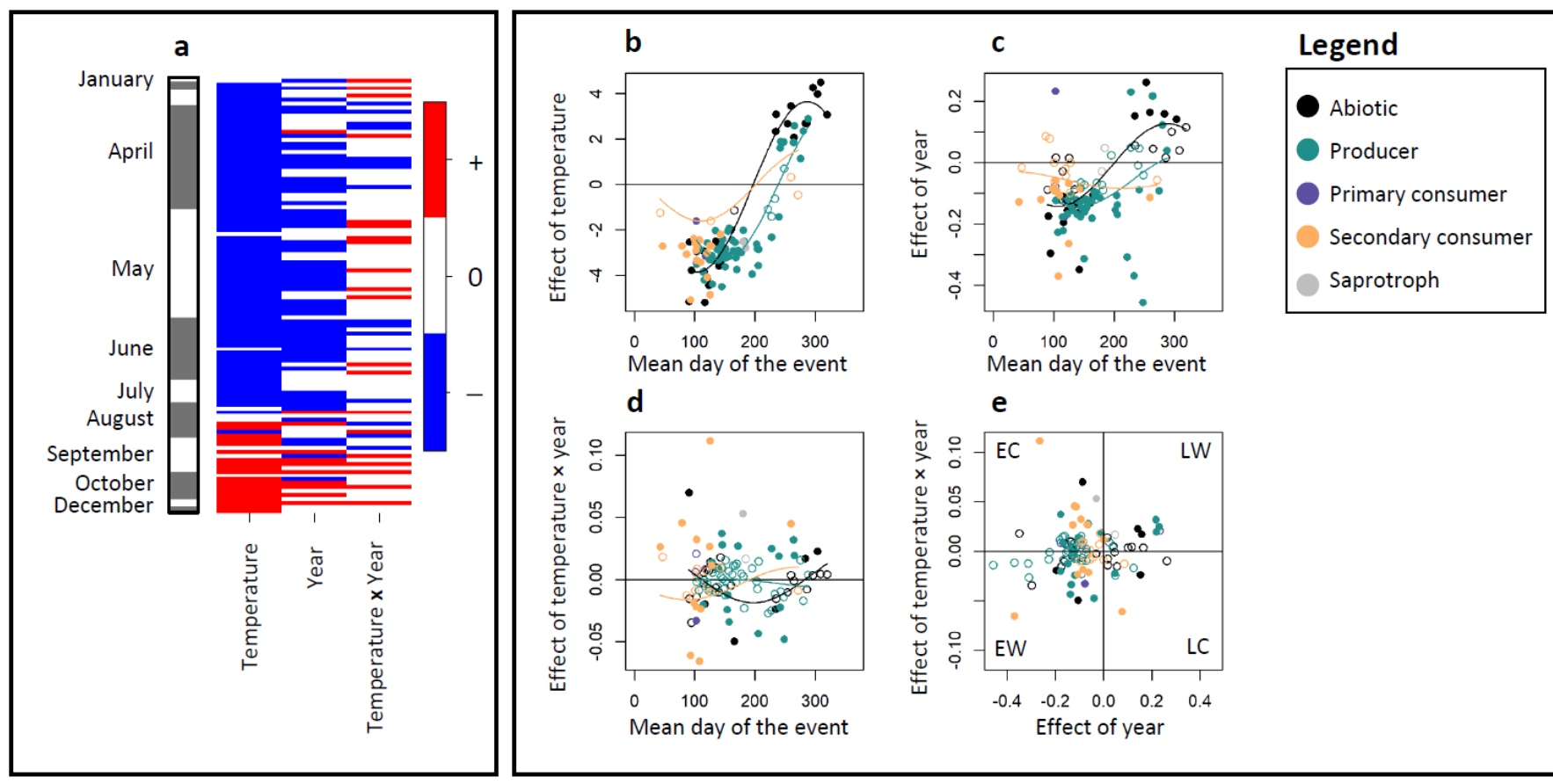

Figure 3. Responses of the events to the fixed effects of mean temperature and year. a, Cases for which the response is positive (red) or negative (blue) with at least $95 \%$ posterior probability, with the events ordered according to their mean date (increasing from top to bottom). The covariates year and temperature have been normalized to have zero mean, so the main effect of the year relates to a site with average temperature, and the main effect of temperature relates to data points collected at the middle of the study period. $\mathbf{b}, \mathbf{c}, \mathbf{d}$ Dependency of event-specific responses on phenological timing (mean day of the year when the event occurs) and on the trophic level of the organism expressing the event (shown by curves in different colours for those groups with at least 5 events). e, Dependency of the response to year x temperature on the response to year. The four quadrats correspond to events that have shifted to earlier especially at cold sites (EC), shifted to earlier especially at warm sites (EW), shifted to later especially at cold sites (LC), and shifted to later especially at warm sites (LW). Filled symbols indicate cases that are either positive or negative with at least $95 \%$ posterior probability. For the effect of year, we show responses in days per year, so that a value of -0.2 represents a shift of two days earlier per decade. For the effect of 
735 temperature, the unit is days per degree Celsius, so that a value of -4 means that the event takes 736 place 8 days earlier in a location with mean temperature $4^{\circ} \mathrm{C}$ compared to a location with mean 737 temperature of $2^{\circ} \mathrm{C}$. 


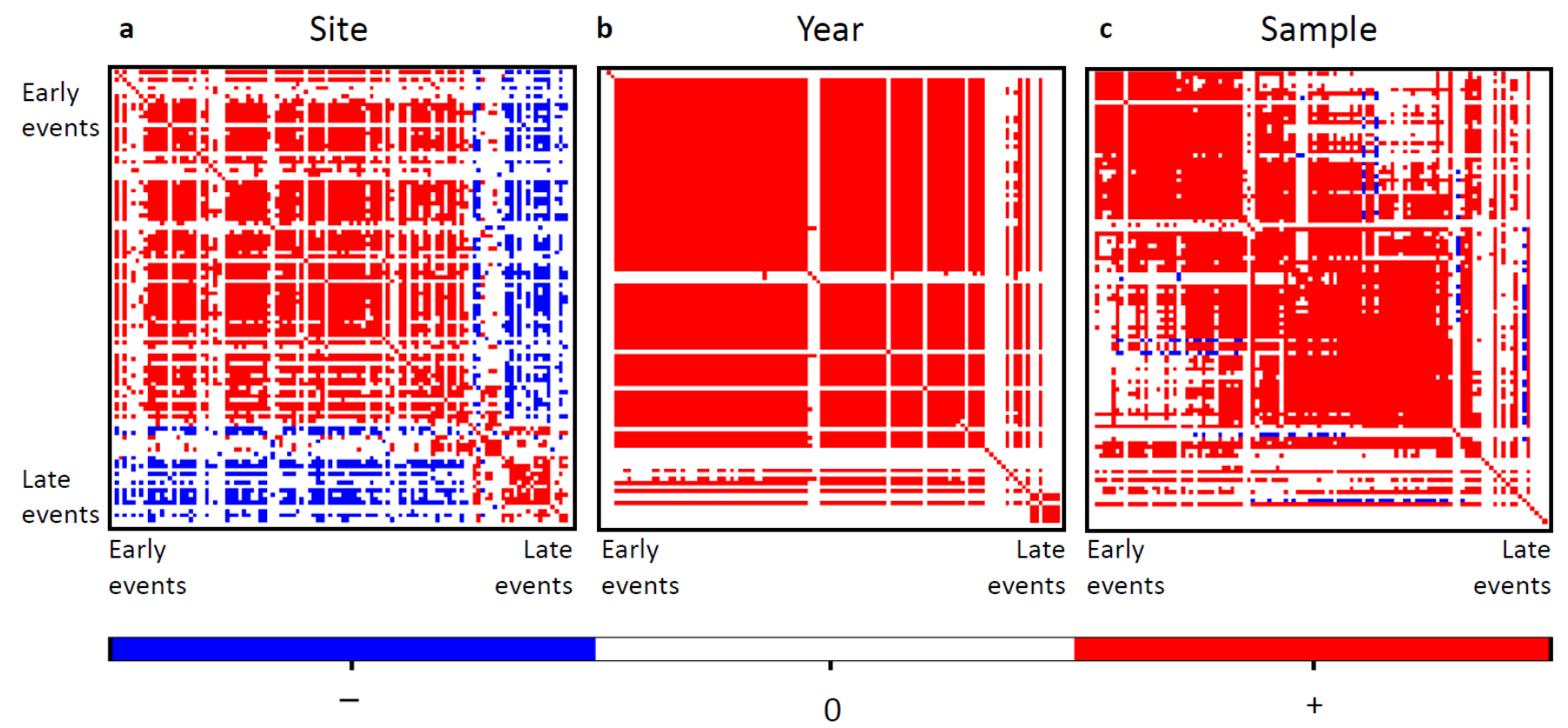

739

Figure 4. Residual associations among events related to random effects. a,b,c Associations at

741 the level of the site (a), the year (b) and the sample (sitexyear; c) The events have been ordered

742 according to their mean date (increasing from left to right, and from top to bottom), and estimates of

743 events associations are measured by residual correlation. Shown in colour are associations showing

744 a positive (red) or negative (blue) association with at least 95\% posterior probability, with

745 remaining cases indicated in white. 

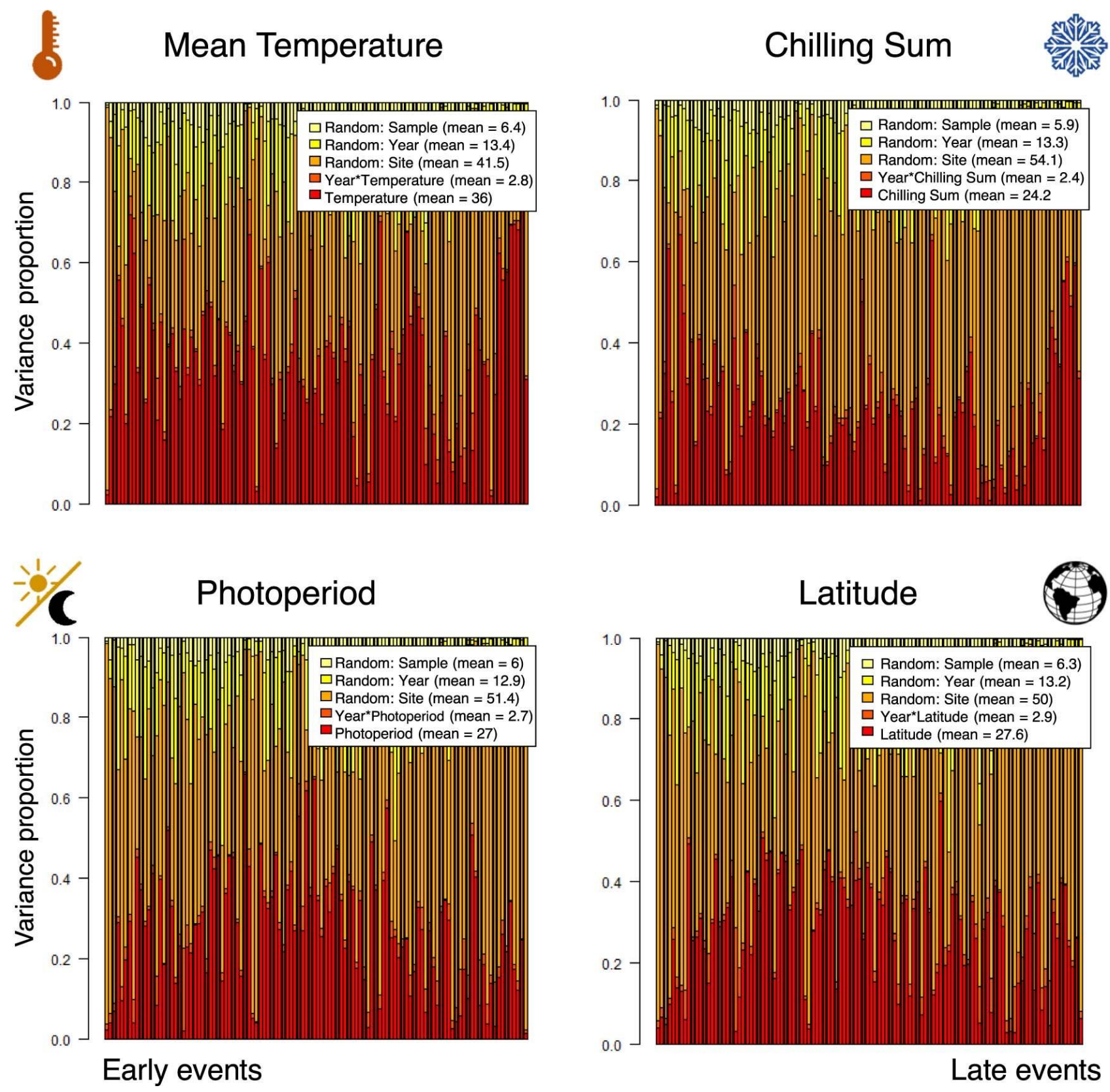

748 Extended Data Fig. 1: Variance partitioning of alternative HMSC-models. Plots show the

749 partitioning of the overall variance of the data into the model components identified in the figure

750 legend. Individual panels show results for models with identical structure but using alternative

751 climatic descriptors of the sampling sites; note that the top-left panel corresponds to Fig. $2 b$ of the

752 main text. Silhouettes adapted from https://thenounproject.com. 

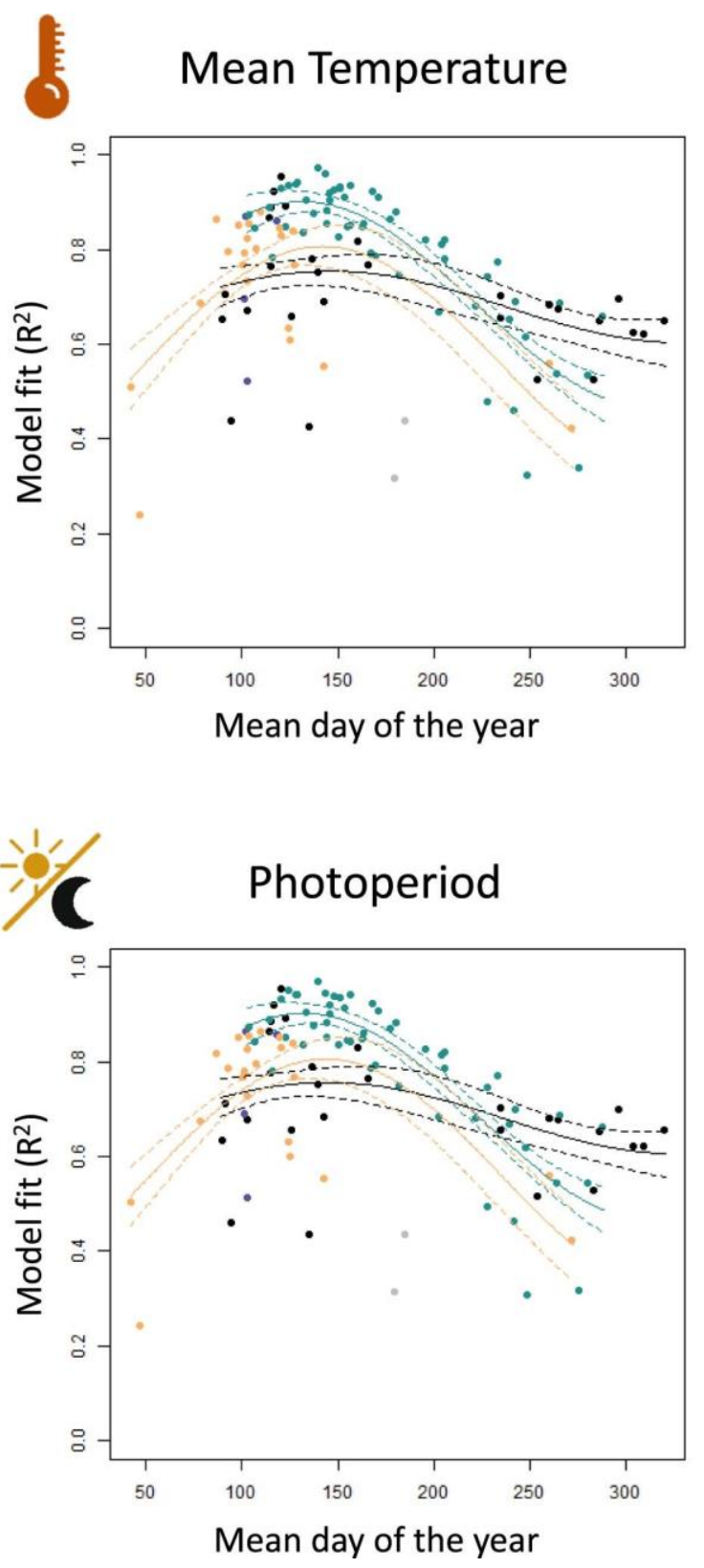

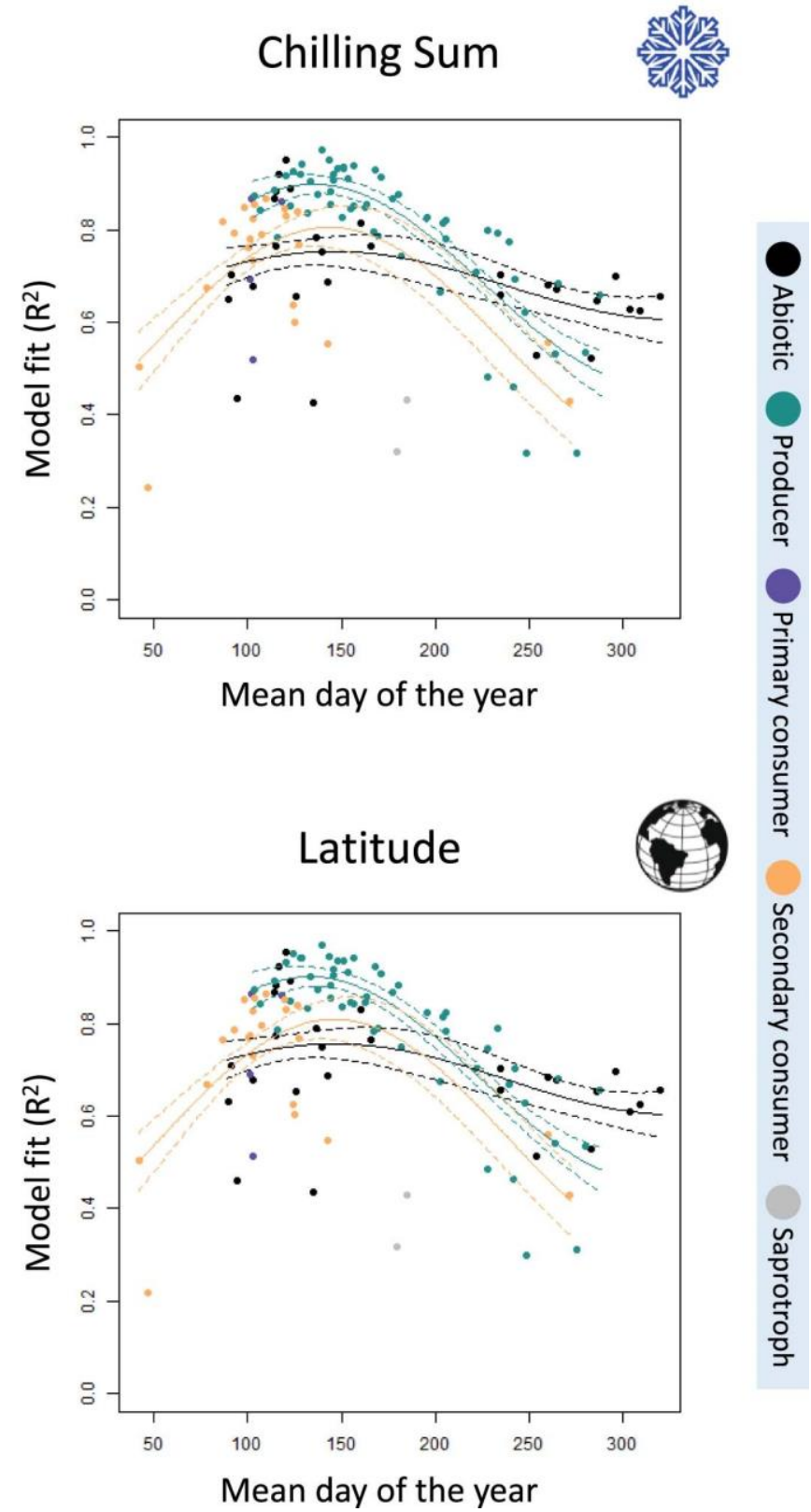

754

755 Extended Data Fig. 2: Explanatory power of alternative HMSC-models. Plots show the degree

756 of determination (R2) as a function of the timing of the event (mean day of the year when the event

757 occurs) and the trophic level of the organism expressing the event (different colours). Curves show

758 second-order models fitted to groups with at least 5 events; continuous lines show mean model

759 prediction and dashed lines \pm one standard error. Individual panels show results for models with

760 identical structure but using alternative climatic descriptors of the sampling sites; note that the top- 
761 left panel corresponds to Fig. 2a of the main text. Silhouettes adapted from

762 https://thenounproject.com.

763 


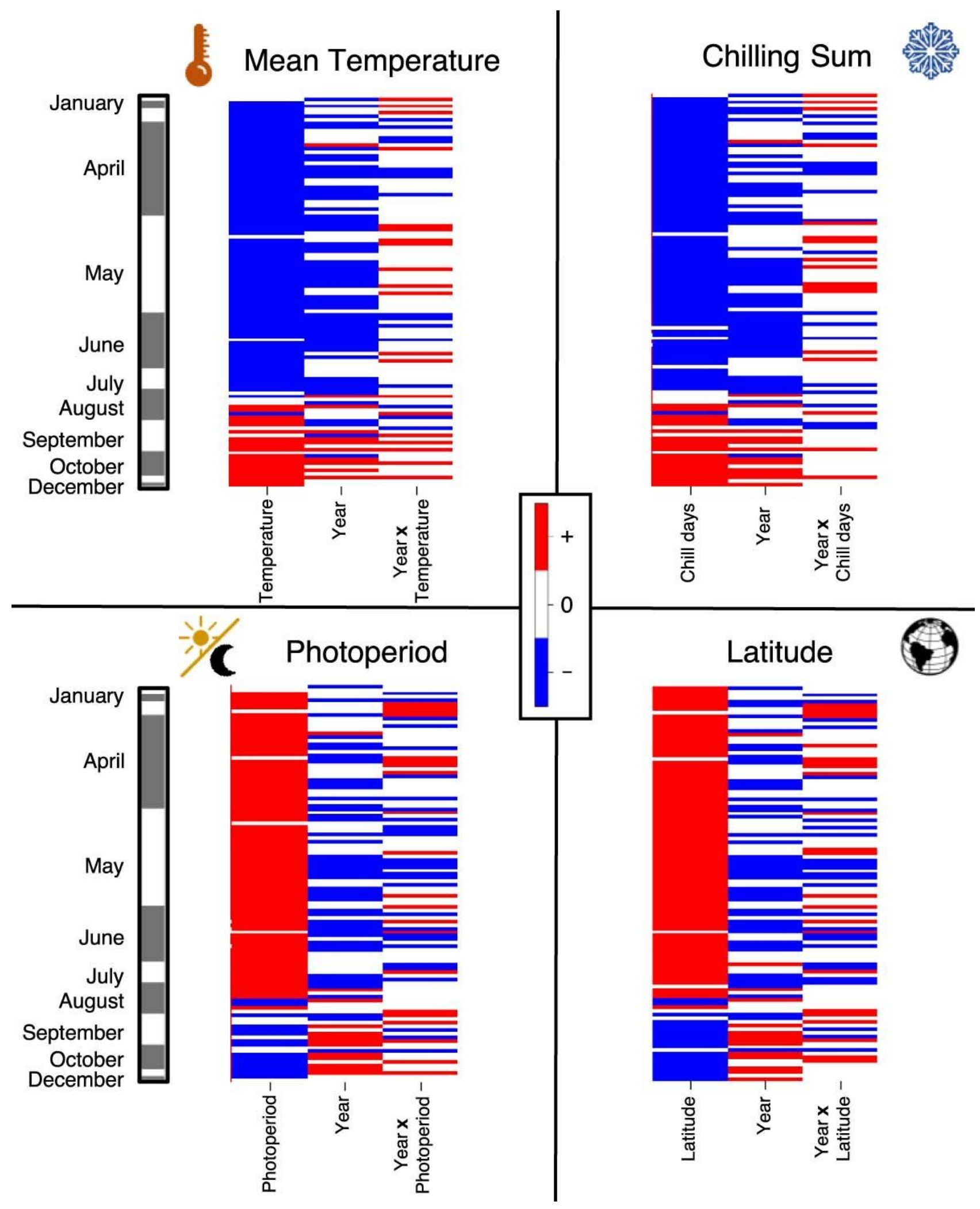

765 Extended Data Fig. 3: The sign of responses of phenological events to the fixed effects

766 included in the HMSC model. Plots show cases for which the response is positive (red) or 
767 negative (blue) with at least $95 \%$ posterior probability. Events have been ordered according to their 768 mean date (increasing from top to bottom). The covariates have been normalized to have zero mean, 769 so that the main effect of the climatic descriptor relates to a data point collected at the middle of the 770 study period, and the main effect of the year relates to a site with an average value of the climatic 771 descriptor. Individual panels show results for models with identical structure but using alternative 772 climatic descriptors of the sampling sites; note that the top-left panel corresponds to Fig. 3a of the 773 main text. Silhouettes adapted from https://thenounproject.com. 


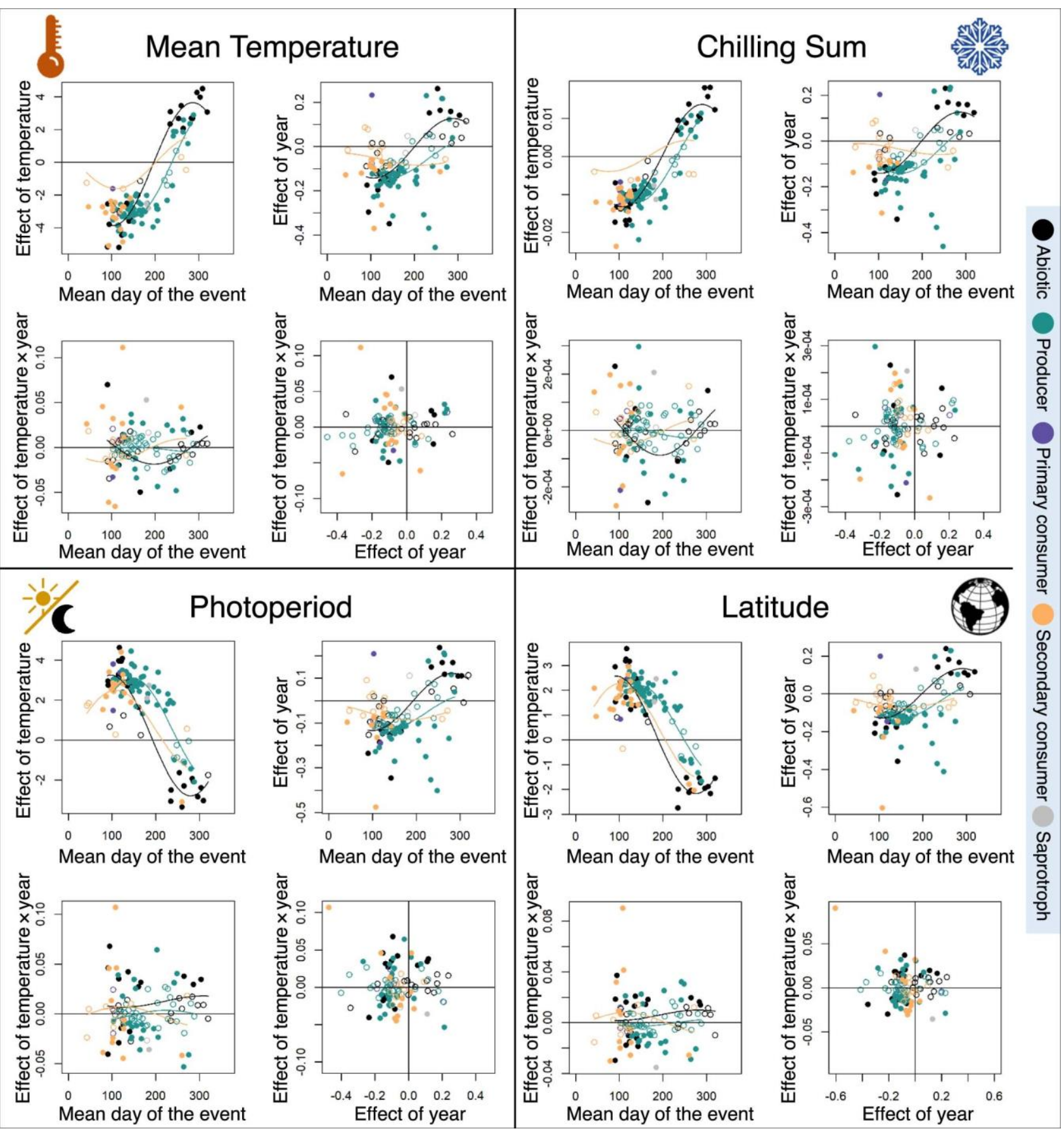

Extended Data Fig. 4: Dependency of event-specific responses on phenological timing and on

777 the trophic level of the organism expressing the event. Individual sections show results for

778 models with identical structure but using alternative climatic descriptors of the sampling sites; note

779 that the top-left section corresponds to Fig. 3b-e of the main text. Within each section, that is for

780 each model, individual panels show the dependency of event-specific responses on phenological 
781 timing (mean day of the year when the event occurs) and on the trophic level of the organism 782 expressing the event (shown by curves in different colours for those groups with at least 5 events).

783 The covariates have been normalized to have zero mean, so that the main effect of the climatic

784 descriptor relates to a data point collected at the middle of the study period, and the main effect of 785 the year relates to a site with an average value of the climatic descriptor. In the bottom-right figure 786 within each quadrat, we show the dependency of the response to year $\times$ temperature on the response 787 to year; here, the four quadrats within the panel correspond to events that have shifted to earlier 788 especially at cold sites (EC), shifted to earlier especially at warm sites (EW), shifted to later 789 especially at cold sites (LC), and shifted to later especially at warm sites (LW). Filled symbols 790 indicate cases that are either positive or negative with at least $95 \%$ posterior probability. Silhouettes 791 adapted from https://thenounproject.com. 


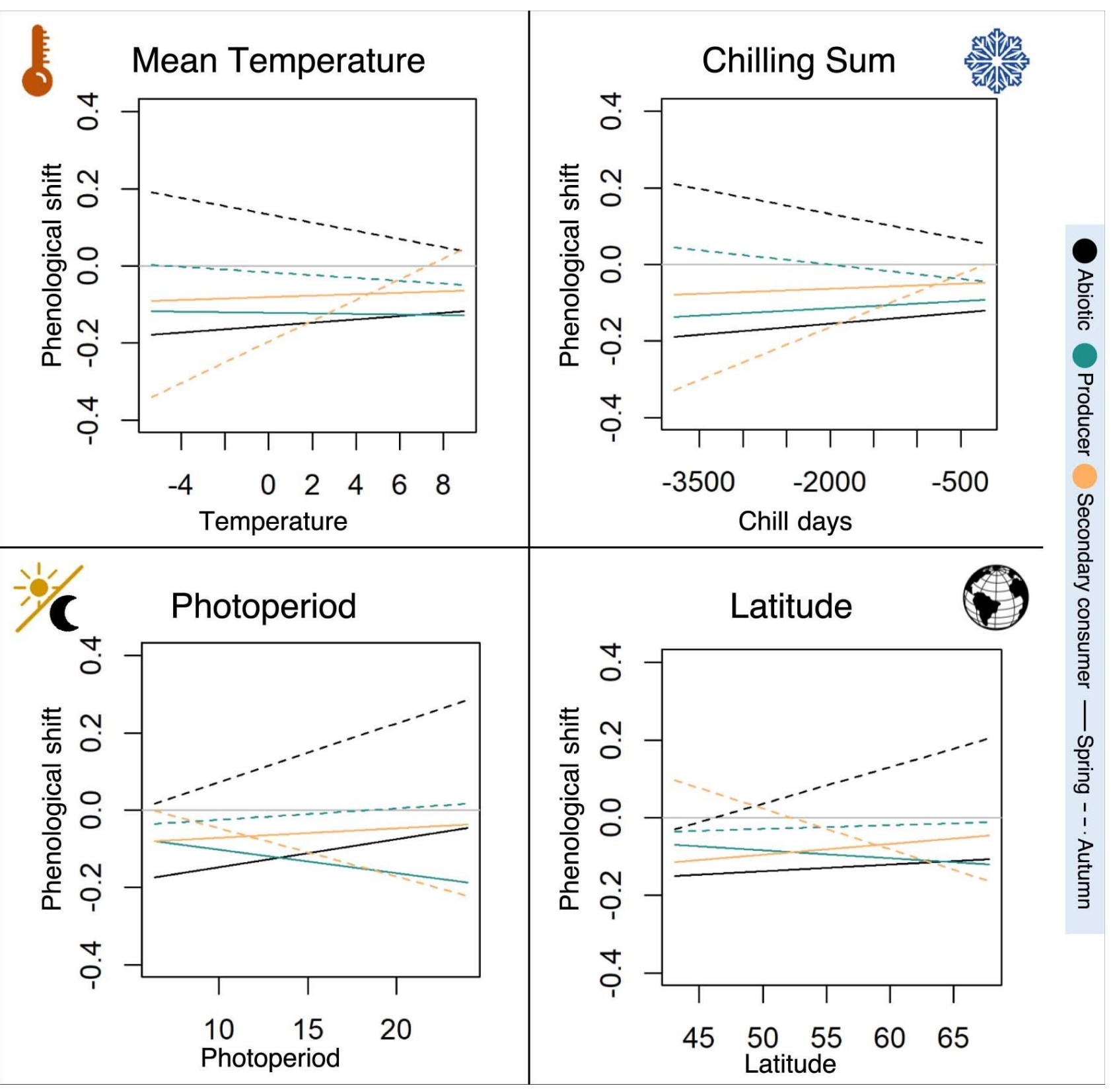

Extended Data Fig. 5: Estimated shift in the phenological timing of events occurring in the spring versus autumn as functions of the average climate descriptors of the site. Plots show the estimated shift in the phenological timing (days per year) among events occurring in the spring

797 (solid line, showing predictions for Day of Year (DOY) 100, that is April 10) versus autumn (dotted 798 line, showing DOY250, that is September 7), plotted against the average climate descriptors of the 799 site. The colours of the lines identify the trophic level of the organism expressing the event.

800 Silhouettes adapted from https://thenounproject.com. 


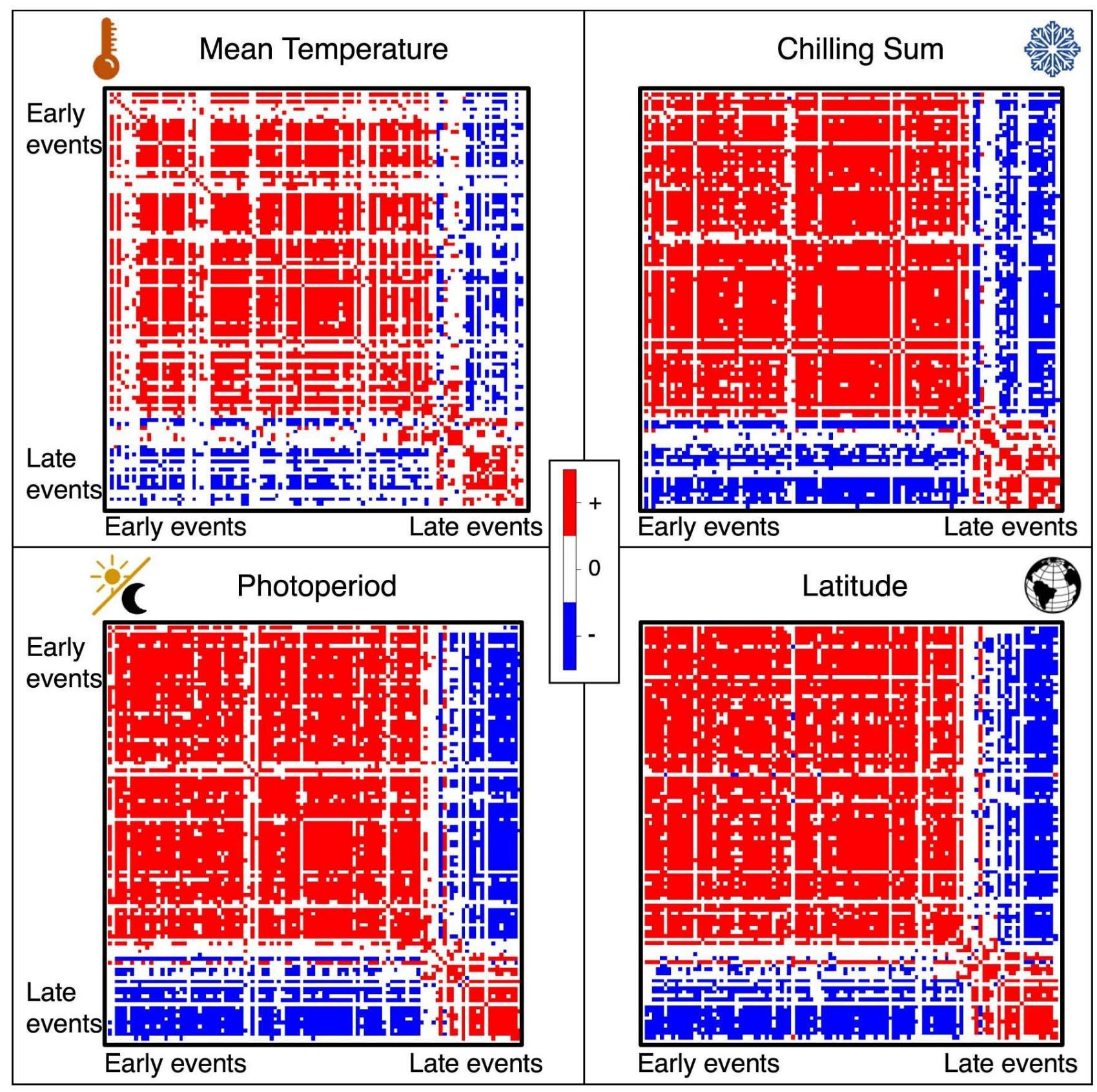

802 Extended Data Fig. 6: Residual associations among events related to the random effects of the

803 site. Plots show the estimates of associations among events measured by residual correlation at the

804 site level. The events have been ordered according to their mean date (increasing from left to right,

805 and from top to bottom). Event-to-event association matrices identify pairs showing a positive (red)

806 or negative (blue) association, shown only if association has either sign with at least $95 \%$ posterior 
807 probability (the remaining cases are shown in white). Note that the top-left panel corresponds to 808 Fig. 4a of the main text. Silhouettes adapted from https://thenounproject.com.

809 


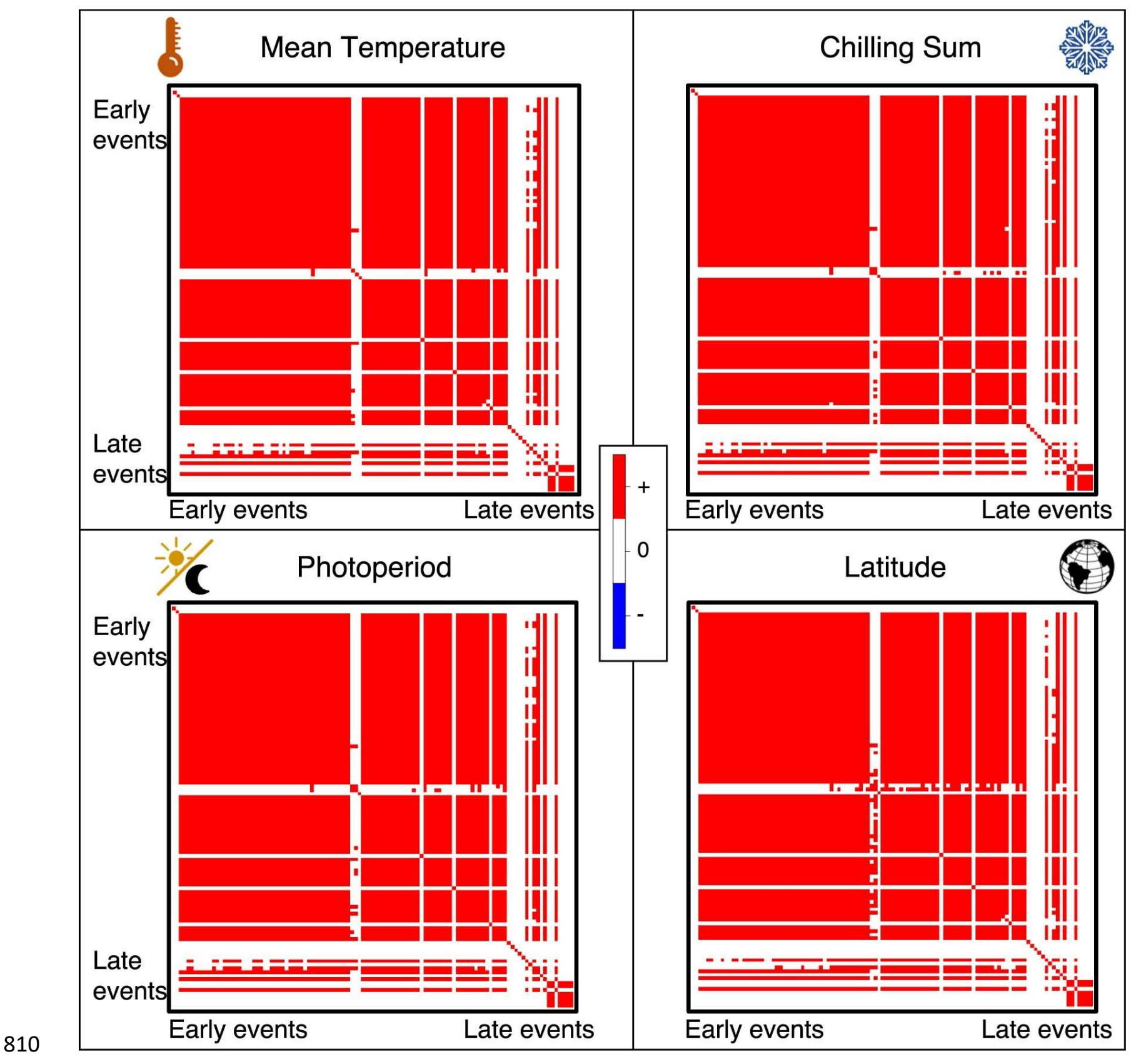

811 Extended Data Fig. 7: Residual associations among events related to the random effects of the

812 year. Plots show the estimates of associations between events measured by residual correlation at

813 the year level. The events have been ordered according to their mean date (increasing from left to

814 right, and from top to bottom). Event-to-event association matrices identify pairs showing a positive

815 (red) or negative (blue) association, shown only if association has either sign with at least 95\% 
816 posterior probability (the remaining cases are shown in white). Note that the top-left panel

817 corresponds to Fig. 4b of the main text. Silhouettes adapted from https://thenounproject.com.

818 


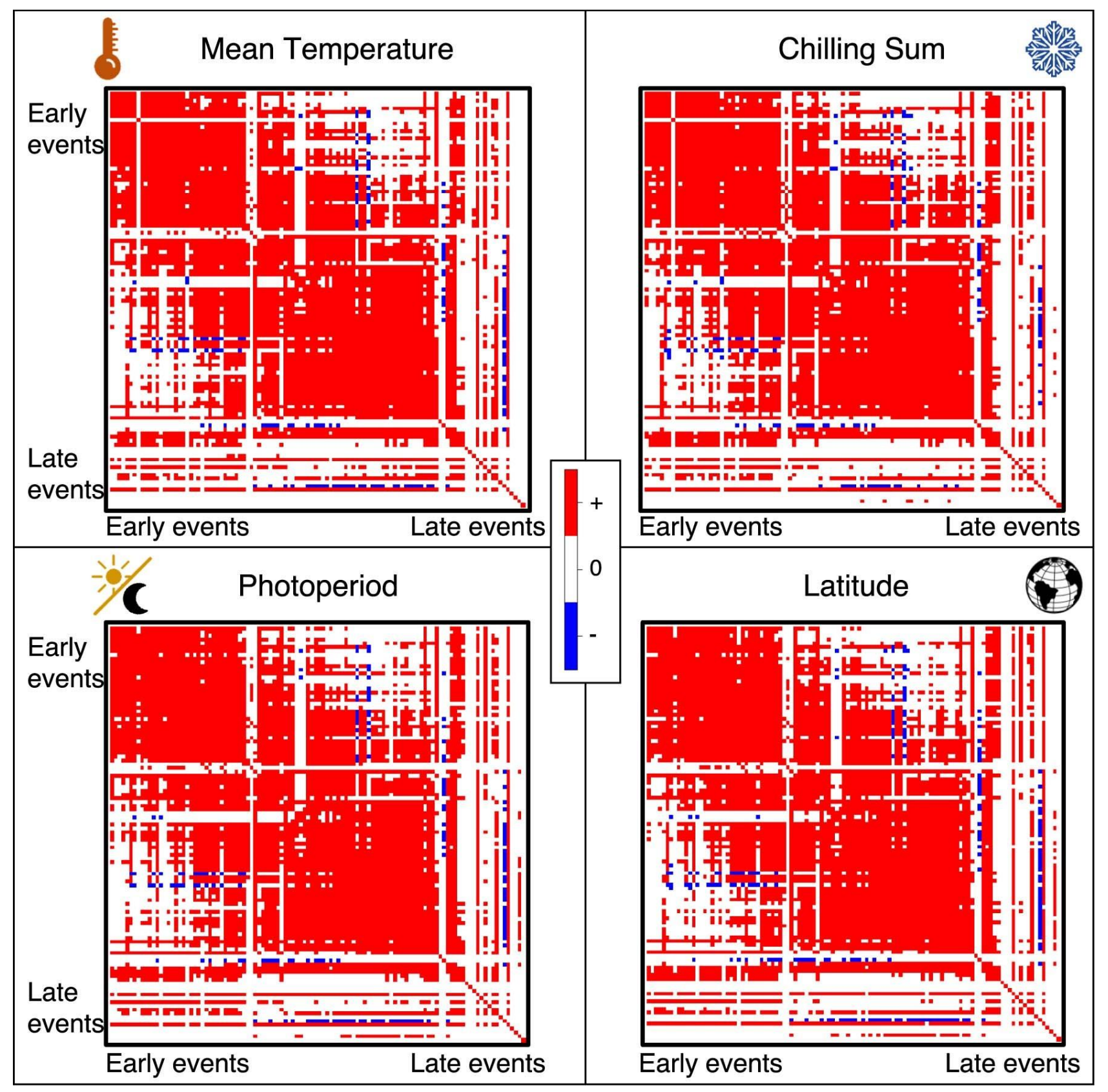

820 Extended Data Fig. 8: Residual associations among events related to the random effects of the

821 year-site pair. Plots show the estimates of associations among events measured by residual

822 correlation at the level of samples, that is yearxsite combinations. The events have been ordered

823 according to their mean date (increasing from left to right, and from top to bottom). Event-to-event

824 association matrices identify pairs showing a positive (red) or negative (blue) association, shown

825 only if association has either sign with at least $95 \%$ posterior probability (the remaining cases are 
826 shown in white). Note that the top-left panel corresponds to Fig. 4c of the main text. Silhouettes 827 adapted from https://thenounproject.com. 


\section{Supporting online material for \\ Phenological shifts of abiotic events, producers and consumers across a continent}

\section{Contents}

Authors

Author affiliations.

Text S1. Classification of phenological events...

Table S1. Classification of events by taxonomic and trophic position 53

Text S2. Description of the HMSC model

Text S3. Convergence of the Markov chain Monte Carlo (MCMC) scheme used for posterior sampling 59

Figure S1. MCMC convergence statistics, measured as potential scale reduction factors and effective sample sizes. 59

References 60 


\section{Authors}

Tomas Roslin ${ }^{1}$, Laura Antao ${ }^{2}$, Maria Hällfors ${ }^{2}$, Evgeniy Meyke ${ }^{3}$, Coong Lo ${ }^{2}$, Gleb Tikhonov ${ }^{4}$, Maria del Mar Delgado ${ }^{5}$, Eliezer Gurarie ${ }^{6}$, Marina Abadonova $^{7}$, Ozodbek Abduraimov ${ }^{8}$, Olga Adrianova $^{9}$, Tatiana Akimova ${ }^{10}$, Muzhigit Akkiev ${ }^{11}$, Aleksandr Ananin ${ }^{12,13}$, Elena Andreeva ${ }^{14}$, Natalia Andriychuk ${ }^{15}$, Maxim Antipin ${ }^{16}$, Konstantin Arzamascev ${ }^{17}$, Svetlana Babina ${ }^{18}$, Miroslav Babushkin ${ }^{19}$, Oleg Bakinn ${ }^{20}$, Anna Barabancova ${ }^{21}$, Inna Basilskaja ${ }^{22}$, Nina Belova ${ }^{23}$, Natalia Belyaeva $^{24}$, Tatjana Bespalova ${ }^{25}$, Evgeniya Bisikalova ${ }^{26}$, Anatoly Bobretsov ${ }^{27}$, Vladimir Bobrov ${ }^{28}$, Vadim Bobrovskyi $^{29}$, Elena Bochkareva ${ }^{30,31}$, Gennady Bogdanov ${ }^{32}$, Vladimir Bolshakov ${ }^{33}$, Svetlana Bondarchuk $^{34}$, Evgeniya Bukharova ${ }^{12,102}$, Alena Butunina ${ }^{25}$, Yuri Buyvolov ${ }^{35}$, Anna Buyvolova ${ }^{36}$, Yuri Bykov $^{37}$, Elena Chakhireva ${ }^{20}$, Olga Chashchina ${ }^{38}$, Nadezhda Cherenkova ${ }^{39}$, Sergej Chistjakov $^{40}$, Svetlana Chuhontseva ${ }^{10}$, Evgeniy A Davydov ${ }^{41,30}$, Viktor Demchenko ${ }^{42}$, Elena Diadicheva $^{42}$, Aleksandr Dobrolyubov ${ }^{43}$, Ludmila Dostoyevskaya ${ }^{44}$, Svetlana Drovnina ${ }^{39}$, Zoya Drozdova $^{37}$, Akynaly Dubanaev ${ }^{45}$, Yuriy Dubrovsky ${ }^{46}$, Sergey Elsukov ${ }^{34}$, Lidia Epova ${ }^{47}$, Olga Ermakova $^{23}$, Olga S Ermakova ${ }^{48}$, Elena Ershkova ${ }^{49,50}$, Aleksandra Esengeldenova ${ }^{25}$, Oleg Evstigneev $^{51}$, Irina Fedchenko ${ }^{52}$, Violetta Fedotova ${ }^{44}$, Tatiana Filatova ${ }^{53}$, Sergey Gashev ${ }^{54}$, Anatoliy Gavrilov $^{55}$, Irina Gaydysh ${ }^{9}$, Dmitrij Golovcov ${ }^{56}$, Nadezhda Goncharova ${ }^{14}$, Elena Gorbunova ${ }^{10}$, Tatyana Gordeeva ${ }^{57,102}$, Vitaly Grishchenko ${ }^{58}$, Ludmila Gromyko ${ }^{34}$, Vladimir Hohryakov ${ }^{59}$, Alexander Hritankov ${ }^{14}$, Elena Ignatenko ${ }^{60}$, Svetlana Igosheva ${ }^{61}$, Uliya Ivanova ${ }^{62}$, Natalya Ivanova ${ }^{63}$, Yury Kalinkin ${ }^{10}$, Evgeniya Kaygorodova ${ }^{51}$, Fedor Kazansky ${ }^{64}$, Darya Kiseleva ${ }^{65}$, Anastasia Knorre $^{14,66}$, Leonid Kolpashikov ${ }^{55}$, Evgenii Korobov ${ }^{67}$, Helen Korolyova ${ }^{10}$, Natalia Korotkikh ${ }^{25}$, Gennadiy Kosenkov ${ }^{59}$, Sergey Kossenko ${ }^{51}$, Elvira Kotlugalyamova ${ }^{68}$, Evgeny Kozlovsky ${ }^{69}$, Vladimir Kozsheechkin ${ }^{14}$, Alla Kozurak ${ }^{15}$, Irina Kozyr ${ }^{23}$, Aleksandra Krasnopevtseva ${ }^{23}$, Sergey Kruglikov $^{51}$, Olga Kuberskaya ${ }^{29}$, Aleksey Kudryavtsev ${ }^{43}$, Elena Kulebyakina ${ }^{70}$, Yuliia Kulsha ${ }^{58}$, Margarita Kupriyanova ${ }^{62}$, Murad Kurbanbagamaev ${ }^{27}$, Anatoliy Kutenkov ${ }^{71}$, Nadezhda Kutenkova ${ }^{71}$, Nadezhda Kuyantseva ${ }^{38,72}$, Andrey Kuznetsov ${ }^{19}$, Evgeniy Larin ${ }^{25}$, Pavel Lebedev ${ }^{44,73}$, Kirill Litvinov $^{74}$, Natalia Luzhkova ${ }^{12}$, Azizbek Mahmudov ${ }^{8}$, Lidiya Makovkina ${ }^{75}$, Viktor Mamontov ${ }^{70}$, Svetlana Mayorova ${ }^{37}$, Irina Megalinskaja ${ }^{27}$, Artur Meydus ${ }^{76,77}$, Aleksandr Minin ${ }^{78,79}$, Oleg Mitrofanov $^{10}$, Mykhailo Motruk ${ }^{80}$, Aleksandr Myslenkov ${ }^{75}$, Nina Nasonova ${ }^{81}$, Natalia Nemtseva ${ }^{19}$, Irina Nesterova ${ }^{34}$, Tamara Nezdoliy ${ }^{62}$, Tatyana Niroda ${ }^{82}$, Tatiana Novikova ${ }^{61}$, Darya Panicheva ${ }^{64}$, Alexey Pavlov ${ }^{20}$, Klara Pavlova ${ }^{60}$, Sergei Podolski ${ }^{60}$, Natalja Polikarpova ${ }^{83}$, Tatiana Polyanskaya ${ }^{84}$, Igor Pospelov $^{28}$, Elena Pospelova ${ }^{55}$, Ilya Prokhorov ${ }^{36}$, Irina Prokosheva ${ }^{85}$, Lyudmila Puchnina ${ }^{52}$, Ivan Putrashyk $^{82}$, Julia Raiskaya ${ }^{76}$, Yuri Rozhkov ${ }^{86}$, Olga Rozhkova ${ }^{86}$, Marina Rudenko ${ }^{87}$, Irina Rybnikova $^{19}$, Svetlana Rykova ${ }^{52}$, Miroslava Sahnevich ${ }^{10}$, Alexander Samoylov ${ }^{39}$, Valeri Sanko ${ }^{42}$, Inna Sapelnikova ${ }^{22}$, Sergei Sazonov ${ }^{88,102}$, Zoya Selyunina ${ }^{89}$, Ksenia Shalaeva ${ }^{59}$, Maksim Shashkov $^{90,63}$, Anatoliy Shcherbakov ${ }^{71}$, Vasyl Shevchyk ${ }^{58}$, Sergej Shubinn ${ }^{91}$, Elena Shujskaja ${ }^{67}$, Rustam Sibgatullin ${ }^{24}$, Natalia Sikkila ${ }^{9}$, Elena Sitnikova ${ }^{51}$, Andrei Sivkov ${ }^{52,102}$, Nataliya Skok ${ }^{62}$, Svetlana Skorokhodova ${ }^{71}$, Elena Smirnova ${ }^{34}$, Galina Sokolova ${ }^{35}$, Vladimir Sopin ${ }^{76}$, Yurii Spasovski $^{92}$, Sergei Stepanov ${ }^{67}$, Vitaliy Stratiy ${ }^{93}$, Violetta Strekalovskaya ${ }^{55}$, Alexander Sukhov ${ }^{71}$, Guzalya Suleymanova $^{94}$, Lilija Sultangareeva ${ }^{68}$, Viktorija Teleganova ${ }^{57}$, Viktor Teplov ${ }^{27,102}$, Valentina Teplova ${ }^{27}$, Tatiana Tertitsa ${ }^{27}$, Vladislav Timoshkin ${ }^{14}$, Dmitry Tirski ${ }^{86}$, Andrej Tolmachev $^{21}$, Aleksey Tomilin ${ }^{95,96}$, Ludmila Tselishcheva ${ }^{91}$, Mirabdulla Turgunov ${ }^{8}$, Yurij Tyukh ${ }^{82}$, Polina Van ${ }^{29}$, Vladimir Van ${ }^{29}$, Aleksander Vasin ${ }^{97}$, Aleksandra Vasina ${ }^{97}$, Anatoliy Vekliuk ${ }^{15}$, Lidia Vetchinnikova $^{88}$, Vladislav Vinogradov ${ }^{98}$, Nikolay Volodchenkov ${ }^{23}$, Inna Voloshina ${ }^{75}$, Tura Xoliqov $^{99}$, Eugenia Yablonovska-Grishchenko ${ }^{58}$, Vladimir Yakovlev ${ }^{10,102}$, Marina Yakovleva ${ }^{71}$, Oksana Yantser ${ }^{62}$, Yurij Yarema ${ }^{82}$, Andrey Zahvatov ${ }^{100}$, Valery Zakharov ${ }^{38}$, Nicolay Zelenetskiy ${ }^{19}$, Anatolii Zheltukhin ${ }^{67}$, Tatyana Zubina ${ }^{10}$, Juri Kurhinen ${ }^{2,88}$ \& Otso Ovaskainen ${ }^{2,101}$ 


\section{Author affiliations}

${ }^{1}$ Swedish University of Agricultural Sciences, Department of Ecology, PO BOX 7044, SE-75007 Uppsala, Sweden, ${ }^{2}$ University of Helsinki, PO BOX 6500014 Helsinki, Finland, ${ }^{3}$ EarthCape OY, Latokartanonkaari 300790 Helsinki, Finland, ${ }^{4}$ Department of Computer Science, Aalto University, PO Box 15400 FI-00076, Finland, ${ }^{5}$ Oviedo University, Research Unit of Biodiversity (UMIB, UOCSIC-PA), Campus Mieres, 33600 Mieres, Spain, ${ }^{6}$ University of Maryland, 3237 BiologyPsychology Building, University of Maryland, College Park, MD 20742, United States, ${ }^{7}$ National Park Orlovskoe Polesie, 303943, Orel region, Hotynetskiy district, Zhuderskiy village, Shkolnaya st. 2, Russian Federation, ${ }^{8}$ Institute of Botany, Academy of sciences of the Republic of Uzbekistan, 100053, Tashkent, Bogi shamol str. 232 V, Uzbekistan, ${ }^{9}$ Kostomuksha Nature Reserve, 186930, Karelia Republic, Kostomuksha, Priozernaya 2, Russian Federation, ${ }^{10}$ Altai State Nature Biosphere Reserve, 649000, Altai Republic, Gorno-Altaysk, Naberezhnyi st., 1, Russian Federation, ${ }^{11}$ Kabardino-Balkarski Nature Reserve, 360000, Kabardino-Balkaria, Cherek District, Mechieva 78, Russian Federation, ${ }^{12}$ FSE Zapovednoe Podlemorye, 671623, Republic of Buryatia, Ust-Bargizin, Lenina st. 71, Russian Federation, ${ }^{13}$ Institute of General and Experimental Biology, Siberian Department, Russian Academy of Sciences, 670047, Republic of Buryatia, Ulan-Ude, Sakhyanovoy str. 6, Russian Federation, ${ }^{14}$ State Nature Reserve Stolby, 660006, Krasnoyarsk region, Krasnoyarsk, Kariernaya 26, Russian Federation, ${ }^{15}$ Carpathian Biosphere Reserve, 90600, Zakarpatska obl., Rakhiv, Krasne Pleso Str. 77, Ukraine, ${ }^{16}$ Nizhne-Svirsky State Nature Reserve, 18700, Leningrad Region, Lodeinoe Pole, Svir River, 1, Russian Federation, ${ }^{17}$ State Nature Reserve Prisursky, 428034, Cheboksary, Lesnoj, 9, Russian Federation, ${ }^{18}$ Zapovednoe Pribajkalje (BajkaloLensky State Nature Reserve, Pribajkalsky National Park), 664050, Irkutsk, Bajkalskaya St., 291B, Russian Federation, ${ }^{19}$ Darwin Nature Biosphere Reserve, 162723, Cherepovets District, Vologda Region, Borok, 44, p/o Ploskovo, Russian Federation, ${ }^{20}$ Volzhsko-Kamsky National Nature Biosphere Rezerve, 422537, Tatarstan Republic, Zelenodolsk District, p/o Raifa, Sadovy, str. Vechova, 1, Russian Federation, ${ }^{21}$ FGBU National Park Shushenskiy Bor, 662710, Krasnoyarsk Region, Shushenskoe, Lugovaja 9, Russian Federation, ${ }^{22}$ Voronezhsky Nature Biosphere Reserve, 394080, Centralnaja usadba, Goszapovednik, Voronezh, Russian Federation, ${ }^{23}$ Baikalsky State Nature Biosphere Reserve, 671220, Buryatia Republic, Kabansky District, Tankhoy, 34 Krasnogvardeyskaya Street, Russian Federation, ${ }^{24}$ Visimsky Nature Biosphere Reserve, 624140, Kirovgrad, Stepana Razina, 23, Russian Federation, ${ }^{25}$ Kondinskie Lakes National Park named after L. F. Stashkevich, 628240, Hanty-Mansijsk district, City Sovietsky, Komsomolski st., 5, Russian Federation, ${ }^{26}$ FSBI United Administration of the Kedrovaya Pad' State Biosphere Nature Reserve and Leopard's Land National Park, 690068, Primorskiy kray, Vladivostok, pr. 100-letiya Vladivostoka 127, Russian Federation, ${ }^{27}$ Pechoro-Ilych State Nature Reserve, 169436, Komi Republic, Trinity-Pechora region, Yaksha, Laninoy Street 8, Russian Federation, ${ }^{28}$ A. N. Severtsov Institute of Ecology and Evolution, 119071, Moscow, Leninsky Prospect 33, Russian Federation, ${ }^{29}$ FGBU Zapovednoye Priamurye, Komsomolskiy Department, 681000, Khabarovskyi krai, Komsomolsk-on-Amur, Mira avenue, 54, Russian Federation, ${ }^{30}$ Tigirek State Nature Reserve, 656043, Barnaul, Nikitina street 111, Russian Federation, ${ }^{31}$ Institute of Systematics and Ecology of Animals of Siberian Branch of Russian Academy of Science, 930091, Novosibirsk, Frunze 11, Russian Federation, ${ }^{32}$ State Nature Reserve Bolshaya Kokshaga, 424038, Mary El Republic, Yoshkar-Ola, Voinov-Internacionalistov 26, Russian Federation, ${ }^{33}$ Institute of Plant and Animal Ecology, Ural Branch, Russian Academy of Sciences, 620100, Ekaterinburg, 8 Marta 202/3, Russian Federation, ${ }^{34}$ Sikhote-Alin State Nature Biosphere Reserve named after K. G. Abramov, 692150, Primorsky krai, Terney, Partizanskaya 44, Russian Federation, ${ }^{35}$ FSBI Prioksko-Terrasniy State Reserve, 142200, Moscow region, Serpukhov district, Danky, Russian Federation, ${ }^{36}$ Lomonosov Moscow State University, 119991, Moscow, Leninskie Gory, Russian Federation, ${ }^{37}$ National park Meshchera, 601501, Vladimir region, Gus-Hrustalnyi, 
Internacionalnaya 111, Russian Federation, ${ }^{38}$ South Urals Federal Research Center of Mineralogy and Geoecology of the Urals Branch of the Russian Academy of Sciences, Ilmeny State Reserve, 456317, Chelyabinskaya oblast, Miass, Russian Federation, ${ }^{39}$ FGBU National Park Kenozersky, 163000, Arkhangelsk, Embankment of the Northern Dvina, 78, Russian Federation, ${ }^{40}$ FGBU GPZ Kologrivskij les im. M.G. Sinicina, 157440, Kostromskaja oblast', Kologriv, Nekrasova 48, Russian Federation, ${ }^{41}$ Altai State University, 656049, Lenin Ave. 61, Barnaul, Russian Federation, ${ }^{42}$ Pryazovskyi National Nature Park, 72312, Zaporiz'ka oblast, Melitopol', Interkulturna Street, 21/1, Ukraine, ${ }^{43}$ State Nature Reserve Privolzhskaya Lesostep, 440031, Penza, Okruzhnaya 12-a, Russian Federation, ${ }^{44}$ Komarov Botanical Institute of the Russian Academy of Sciences (BIN RAS), 197376, Saint Petersburg, Professora Popova 2, Russian Federation, ${ }^{45}$ Sary-Chelek State Nature Reserve, 715705, Dzalal-Abad region, Aksu district, Arkyt village, Kyrgyzstan, ${ }^{46}$ Institute for Evolutionary Ecology NAS Ukraine, 03143, Kiev, Lebedeva 37, Ukraine, ${ }^{47}$ FGBU State Nature Reserve Kuznetsk Alatau, 652888, Kemerovo region, Mezhdurechensk, Shakhterov 33-1, Russian Federation, ${ }^{48}$ Kerzhenskiy State Nature Biosphere Reserve, 603001, Nizhny Novgorod, Rozhdestvenskaya 23, Russian Federation, ${ }^{49}$ FSBI United Administration of the Mordovia State Nature Reserve and National Park Smolny, 430005, Republic of Mordovia, Saransk, Krasnaya 30, Russian Federation, ${ }^{50}$ Ogarev Mordovia State University, 430005, Republic of Mordovia, Saransk, Bolshevistskaya 68, Russian Federation, ${ }^{51}$ Bryansk Forest Nature Reserve, 242180, Bryansk region, Suzemka district, Nerussa St., Zapovednaya street, 2, Russian Federation, ${ }^{52}$ Pinezhsky State Nature Reserve, 164610, Arhangel region, Pinezkiy district, Pinega, Pervomayskaya street, 123 A, Russian Federation, ${ }^{53}$ The Central Chernozem State Biosphere Nature Reserve named after Professor V.V. Alyokhin, 305528 Kurskiy region, Kurskiy district, p/o Zapovednoe, Russian Federation, ${ }^{54}$ Tyumen State University, 625043, Tyumen, Pirogova str., 3, Russian Federation, ${ }^{55}$ Reserves of Taimyr, 666300, Norilsk, str. Talnakhskaya, entrance 2, Russian Federation, ${ }^{56}$ Chatkalski National Park, 100059, Toshkent, Shota Rustaveli St., 144-34, Uzbekistan, ${ }^{57}$ National Park Ugra, 248007, Kaluga, Prigorodnoe lesnichestvo, 3a, Russian Federation, ${ }^{58}$ Kaniv Nature Reserve, 19000, Kaniv, Shevchenko str. 108, Ukraine, ${ }^{59}$ Smolenskoe Poozerje National Park, 216270, Smolensk Region, Demidovskiy district, Przhevalskoe, Gurevitch street 19, Russian Federation, ${ }^{60}$ FSBI Zeya State Nature Reserve, 676246, Stroitelnaya str. 71, Zeya, Amurskaya Oblast, Russian Federation, ${ }^{61}$ Polistovsky State Nature Reserve, 182840, Pskov region, Bezhanitsy district, Bezhanitsy Sovetskaya street, 9B, Russian Federation, ${ }^{62}$ Ural State Pedagogical University, 620017, Yekaterinburg, prosp. Kosmonavtov, 26, Russian Federation, ${ }^{63}$ Institute of Mathematical Problems of Biology RAS - the Branch of the Keldysh Institute of Applied Mathematics of Russian Academy of Sciences, 142290, Moscow Region, Pushchino, Prof. Vitkevicha 1, Russian

Federation, ${ }^{64}$ Kronotsky Federal Nature Biosphere Reserve, 684000, Kamchatka region, Yelizovo, Ryabikova street 48, Russian Federation, ${ }^{65}$ Zhiguli Nature Reserve, 445362, Samara region, P. Bakhilova Polyana, Zhigulyovskaya 1, Russian Federation, ${ }^{66}$ Institute for Ecology and Geography, Siberian Federal University, 660041, Krasnoyarsk, 79 Svobodny pr., Russian Federation, ${ }^{67}$ Central Forest State Nature Biosphere Reserve, 172521, Tver region, Nelidovo district, Zapovedniy village, Russian Federation, ${ }^{68}$ National Park Bashkirija, 453870, Bashkortostan Republic, Meleuzovskiy district, Nurgush, Abubakirova 1, Russian Federation, ${ }^{69}$ State Nature Reserve Kurilsky, 694500 , Sakhalin, Juzhno-Kurilsk, Zarechnaya 5, Russian Federation, ${ }^{70}$ Vodlozersky National Park, 185002 , Karelia, Petrozavodsk, Parkovaya 44, Russian Federation, ${ }^{71}$ State Nature Reserve Kivach, 186220, Kondopoga District, Republic of Karelia, Russian Federation, ${ }^{72}$ South-Ural Federal University, 4563304, Chelyabinskaya oblast, Miass, ul. Kalinina 37, Russian Federation, ${ }^{73}$ Saint-Petersburg State Forest Technical University, 194021, St. Petersburg, Institutsky per. 5, 1-338-3, Russian Federation, ${ }^{74}$ Astrakhan Biosphere Reserve, 414021, Astrakhan, Tsaerv River Bank 119, Russian Federation, ${ }^{75}$ FSBI United Administration of the Lazovsky State Reserve and national park Zov Tigra, 692980, Primorskiy Krai, Lazovskiy District, Lazo, Centralnaya, 56, Russian Federation, ${ }^{76}$ State Nature Reserve Tungusskiy, 660028, Krasnoyarsk region, Krasnoyarsk Street 27 
19, Russian Federation, ${ }^{77}$ Krasnoyarsk State Pedagogical University named after V.P. Astafyev, 660049, Krasnoyarsk, Ada Lebedeva st. 89, Russian Federation, ${ }^{78}$ Institute of Geography, Russian Academy of Sciences, 119017, Moscow, Staromonetniy 29, Russian Federation, ${ }^{79}$ Koltzov Institute of Developmental Biology, Russian Academy of Sciences, 119334, Moscow, Vavilov Street 26, Russian Federation, ${ }^{80}$ Carpathian National Nature Park, 78500, Ivano-Frankivsk region, Yaremche, V. Stusa street 6, Ukraine, ${ }^{81}$ State Environmental Institution National Park Braslav lakes, 211970, Vitebsk region, Braslav, Dachnaya 1, Belarus, ${ }^{82}$ National Park Synevyr, 90041, Zakarpattia Region, Mizhhirs'kyi district, Synevyr-Ostriki, Ukraine, ${ }^{83}$ Pasvik State Nature Reserve, 184421, Murmansk region, Nikel, Gvardeyskiy Ave. 43, Russian Federation, ${ }^{84}$ Mari Chodra National Park, 425090, Mari El Republic, Zvenigovsky District, Krasnogorsky Settlement, Tsentralnaya Street, 73, Russian Federation, ${ }^{85}$ State Nature Reserve Vishersky, 618590, Perm region, Krasnovishersk, Gagarina street 36B, Russian Federation, ${ }^{86}$ State Nature Reserve Olekminsky, 678100, Republic Sakha, Olekminsk, Filatova 6, Russian Federation, ${ }^{87}$ Crimea Nature Reserve, 298514, Alushta, Partizanskaya, 42, Republic of Crimea, ${ }^{88}$ Forest Research Institute Karelian Research Centre Russian Academy of Sciences, 185910, Karelia, Petrozavodsk, Pushkinskaya 11, Russian Federation, ${ }^{89}$ Black Sea Biosphere Reserve, 75600, Khersons'ka oblast, Hola Prystan', Mikhail Lermontov 1, Ukraine, ${ }^{90}$ Institute of Physicochemical and Biological Problems in Soil Sciences Russian Academy of Science, 142290, Moscow Region, Pushchino, Institutskaya 2, Russian Federation, ${ }^{91}$ State Nature Reserve Nurgush, 610002, Kirov, Lenina street, 129a, Russian Federation, ${ }^{92}$ Caucasian State Biosphere Reserve of the Ministry of Natural Resources, 385000, Adygea Republik, Maykop, Sovetskaya str. 187, Russian Federation, ${ }^{93}$ National Nature Park Vyzhnytskiy, 59200, Chernivtsi Region, Vyzhnytsya District, Berehomet, Street Central 27 a, Ukraine, ${ }^{94}$ National Park Khvalynsky, 412780, Region Saratov, Khvalynsk Sity, Oktyberskya Street, 2b, Russian Federation, ${ }^{95}$ State Research Center Arctic and Antarctic Research Institute, 199397, Saint Petersburg, Bering st. 38, Russian Federation, ${ }^{96}$ Information-Analytical Centre for Protected Areas, 123242, Moscow, Kapranova side-street 3, ${ }^{97}$ State Nature Reserve Malaya Sosva, 628242, Tjumen region, Sovetskiy, Lenina str., 46, Russian Federation, ${ }^{98}$ Krasnoyarsk State Medical University named after Prof. V.F.Voino-Yasenetsky, 660022, Krasnoyarsk region, Krasnoyarsk, Partizana Zhelezniaka, 1, Russian Federation, ${ }^{99}$ Surhanskiy State Nature Reserve, 191404, Surhandarja region, Sherabad, Agahi, 1, Uzbekistan, ${ }^{100}$ Mordovia State Nature Reserve, 431230, Mordovia Republic, Temnikov region, village Pushta, Russian Federation, ${ }^{101}$ Centre for Biodiversity Dynamics, Department of Biology, Norwegian University of Science and Technology, N-7491 Trondheim, Norway. ${ }^{102}$ Evgeniya Bukharova, Tatyana Gordeeva, Sergei Sazonov, Andrei Sivkov, Viktor Teplov, and Vladimir Yakovlev are deceased.

* Corresponding author: tomas.roslin@slu.se 


\section{Text S1. Classification of phenological events}

All events were classified into four trophic levels according to the organism expressing the event: primary producers (plants), primary consumers (herbivorous insects) and secondary consumers (predatory insects, amphibians, birds, mammals). Saprotrophs (fungi) were included as a separate level, as commonly feeding on the remains of multiple other levels, and abiotic events as a separate category. Species classification was based on the basic biology of the juvenile stage. For holometaboulous organisms (such as insects undergoing full metamorphosis), the juvenile stage is typically the one consuming the most resources for growth, and the same applies for birds.

Specifically, in classifying all birds as secondary consumers, we note that while some species may be mainly herbivorous as adults, their young are dependent on protein-rich arthropods for growth ${ }^{1}$. Since we expect breeding-time resources to be more decisive for these species' phenology than the needs of the adults, we have used the diet of the young for our trophic classification.

\section{Table S1. Classification of events by taxonomic and trophic position}

The table shows the identity of the species and events included in the analyses, with their taxonomic position, trophic level and relative timing (here expressed as the mean Day of the Year when the phenological event first occurred; mean DOY).

\begin{tabular}{|c|c|c|c|}
\hline Taxon (+ meteo events) & Trophic level & Event scored & $\begin{array}{l}\text { Mean } \\
\text { DOY }\end{array}$ \\
\hline \multicolumn{4}{|l|}{ AVES } \\
\hline \multicolumn{4}{|l|}{ Alaudidae } \\
\hline Alauda arvensis & Secondary consumer & 1 st song* & 93.14 \\
\hline \multicolumn{4}{|l|}{ Anatidae } \\
\hline Anas crecca & Secondary consumer & 1st occurrence & 119.73 \\
\hline Anas platyrhyncos & Secondary consumer & 1st occurrence* & 101.64 \\
\hline Cygnus cygnus & Secondary consumer & 1st occurrence & 107.42 \\
\hline Bucephala clangula & Secondary consumer & 1st occurrence & 109.81 \\
\hline \multicolumn{4}{|l|}{ Apodidae } \\
\hline Apus apus & Secondary consumer & 1st occurrence* & 142.78 \\
\hline \multicolumn{4}{|l|}{ Charadriidae } \\
\hline Vanellus vanellus & Secondary consumer & 1st occurrence & 100.43 \\
\hline \multicolumn{4}{|l|}{ Corvidae } \\
\hline Corvus frugilegus & Secondary consumer & 1st occurrence & 78.54 \\
\hline \multicolumn{4}{|l|}{ Cuculidae } \\
\hline Cuculus canorus & Secondary consumer & 1st song* & 127.64 \\
\hline \multicolumn{4}{|l|}{ Fringillidae } \\
\hline Fringilla coelebs & Secondary consumer & 1st occurrence* & 98.12 \\
\hline \multicolumn{4}{|l|}{ Gruidae } \\
\hline Grus grus & Secondary consumer & 1st occurrence & 103.00 \\
\hline \multicolumn{4}{|l|}{ Hirundinidae } \\
\hline \multirow[t]{2}{*}{ Hirundo rustica } & \multirow[t]{2}{*}{ Secondary consumer } & 1st occurrence* & 124.57 \\
\hline & & Last occurrence & 259.44 \\
\hline \multicolumn{4}{|l|}{ Motacillidae } \\
\hline \multirow[t]{2}{*}{ Motacilla alba } & \multirow[t]{2}{*}{ Secondary consumer } & 1st occurrence* & 103.11 \\
\hline & & Last occurrence & 271.23 \\
\hline
\end{tabular}




\begin{tabular}{|l|l|l|l|}
\hline Muscicapidae & & & \\
\hline Luscinia luscinia & Secondary consumer & 1st song & 125.15 \\
\hline Paridae & & & \\
\hline Parus major & Secondary consumer & 1 st song & 42.33 \\
\hline Picidae & & & 46.91 \\
\hline Dendrocopos major & Secondary consumer & Start of drumming & \\
\hline Sturnidae & & & 86.51 \\
\hline Sturnus vulgaris & Secondary consumer & 1st occurrence & \\
\hline
\end{tabular}

\begin{tabular}{|l|l|l|l|}
\hline FUNGUS & & & \\
\hline Boletaceae & & & \\
\hline Leccinum aurantiacum & Saprotroph & 1st occurrence & 179.67 \\
\hline Leccinum scabrum & Saprotroph & 1st occurrence & 184.60 \\
\hline
\end{tabular}

\begin{tabular}{|l|l|l|l|}
\hline INSECTA & & & \\
\hline Apidae & & & \\
\hline Bombus $s p$ & Primary consumer & 1 st occurrence & 118.04 \\
\hline Culicidae & & & \\
\hline Culicidae $s p$ & Secondary consumer & 1 st occurrence & 126.78 \\
\hline Formicidae & & & \\
\hline Formica rufa & Secondary consumer & Livening up & 103.83 \\
\hline Nymphalidae & & & 101.22 \\
\hline Aglais urticae & Primary consumer & 1st occurrence & \\
\hline Pieridae & & & 102.30 \\
\hline Gonepteryx rhamni & Primary consumer & 1st occurrence & \\
\hline
\end{tabular}

\begin{tabular}{|l|l|l|l|}
\hline MAMMALIA & & & \\
\hline Ursidae & & & \\
\hline Ursus arctos & Secondary consumer & Awakening & 102.49 \\
\hline
\end{tabular}

\begin{tabular}{|c|c|c|c|}
\hline PLANTAE & & & \\
\hline \multicolumn{4}{|l|}{ Asparagaceae } \\
\hline Convallaria majalis & Producer & Onset of blooming & 144.47 \\
\hline Maianthemum bifolium & Producer & Onset of blooming & 167.92 \\
\hline \multicolumn{4}{|l|}{ Astaraceae } \\
\hline Leucanthemum vulgare & Producer & Onset of blooming & 169.79 \\
\hline Taraxacum officinale & Producer & Onset of blooming & 131.87 \\
\hline Tussilago farfara & Producer & Onset of blooming & 106.95 \\
\hline \multicolumn{4}{|l|}{ Betulaceae } \\
\hline \multirow[t]{7}{*}{ Betula pendula } & \multirow[t]{7}{*}{ Producer } & Onset of sap bleeeding & 103.36 \\
\hline & & Onset of budburst & 120.20 \\
\hline & & Onset of leaf unfolding & 128.36 \\
\hline & & Onset of autumn colouring & 242.07 \\
\hline & & Onset of leaf fall & 247.69 \\
\hline & & Full autumn colouring of leaves & 264.94 \\
\hline & & Leaf fall end & 287.69 \\
\hline \multicolumn{4}{|l|}{ Caprifoliaceae } \\
\hline Lonicera caerulea & & Onset of blooming & 150.41 \\
\hline \multicolumn{4}{|l|}{ Ericaceae } \\
\hline Oxycoccus palustris & Producer & Onset of blooming* & 163.29 \\
\hline Ledum palustre & Producer & Onset of blooming & 156.75 \\
\hline Vaccinium myrtillus & Producer & Onset of blooming & 145.35 \\
\hline
\end{tabular}




\begin{tabular}{|c|c|c|c|}
\hline & \multirow{5}{*}{ Producer } & Onset of fruiting (ripe)* & 195.23 \\
\hline & & Mass fruiting & 204.14 \\
\hline \multirow[t]{3}{*}{ Vaccinium vitis-idaea } & & Onset of blooming* & 162.31 \\
\hline & & Onset of fruiting (ripe) & 227.44 \\
\hline & & Mass fruiting & 239.47 \\
\hline \multicolumn{4}{|l|}{ Fabaceae } \\
\hline Caragana arborescens & Producer & Onset of blooming & 148.28 \\
\hline \multicolumn{4}{|l|}{ Grossulariaceae } \\
\hline \multirow[t]{2}{*}{ Ribes nigrum } & \multirow[t]{2}{*}{ Producer } & Onset of blooming* & 145.99 \\
\hline & & Onset of fruiting (ripe) & 205.27 \\
\hline \multicolumn{4}{|l|}{ Malvaceae } \\
\hline \multirow[t]{2}{*}{ Tilia cordata } & \multirow[t]{2}{*}{ Producer } & Onset of leaf unfolding & 129.07 \\
\hline & & Onset of blooming* & 181.85 \\
\hline \multicolumn{4}{|l|}{ Oleaceae } \\
\hline Syringa vulgaris & Producer & Onset of blooming & 150.87 \\
\hline \multicolumn{4}{|l|}{ Onagraceae } \\
\hline Epilobium angustifolium & Producer & Onset of blooming & 180.06 \\
\hline \multicolumn{4}{|l|}{ Pinaceae } \\
\hline Pinus sylvestris & Producer & onset of blooming* & 153.18 \\
\hline \multicolumn{4}{|l|}{ Ranunculaceae } \\
\hline Caltha palustris & Producer & Onset of blooming & 133.70 \\
\hline Trollius europaeus & Producer & Onset of blooming & 150.87 \\
\hline \multicolumn{4}{|l|}{ Rosaceae } \\
\hline \multirow[t]{2}{*}{ Fragaria vesca } & \multirow[t]{2}{*}{ Producer } & Onset of blooming* & 144.48 \\
\hline & & Onset of fruiting (ripe) & 176.94 \\
\hline \multirow[t]{8}{*}{ Prunus padus } & \multirow[t]{8}{*}{ Producer } & Onset of budburst & 114.10 \\
\hline & & Onset of leaf unfolding & 124.06 \\
\hline & & Onset of blooming* & 139.22 \\
\hline & & Onset of mass blooming & 143.10 \\
\hline & & Onset of fruiting (ripe) & 202.32 \\
\hline & & Onset of autumn colouring & 221.38 \\
\hline & & Onset of leaf fall & 232.95 \\
\hline & & Leaf fall end & 275.01 \\
\hline Rosa acicularis & Producer & Onset of blooming & 171.34 \\
\hline Rubus chamaemorus & Producer & Onset of blooming* & 154.64 \\
\hline \multirow[t]{2}{*}{ Rubus idaeus } & \multirow[t]{2}{*}{ Producer } & Onset of blooming* & 166.83 \\
\hline & & Onset of fruiting (ripe) & 205.81 \\
\hline \multirow[t]{2}{*}{ Sorbus aucuparia } & Producer & Onset of blooming* & 156.06 \\
\hline & & Onset of fruiting (ripe) & 227.55 \\
\hline Salicaceae & & & \\
\hline Salix caprea & Producer & Onset of blooming* & 123.08 \\
\hline Populus tremula & Producer & Onset of blooming & 115.70 \\
\hline & & Onset of leaf unfolding & 137.18 \\
\hline & & Onset of autumn colouring & 241.60 \\
\hline & & Onset of leaf fall & 248.20 \\
\hline & & Full autumn colouring of leaves & 263.45 \\
\hline & & Leaf fall end & 280.00 \\
\hline REPTILIA & & & \\
\hline Squamata & & & \\
\hline Zootoca vivipara & Secondary consumer & 1st occurrence & 120.50 \\
\hline METEO & & & \\
\hline
\end{tabular}




\begin{tabular}{|c|c|c|}
\hline \multirow[t]{2}{*}{ Thaw } & $\begin{array}{l}\text { 1st thawed patches to an earth surface } \\
\text { around trunks of trees }\end{array}$ & 90.00 \\
\hline & 1st thawed patches on open places & 103.11 \\
\hline \multirow[t]{14}{*}{ Temperature } & $\begin{array}{l}\text { Daily average air temperature - } \\
\text { transition above } 0\end{array}$ & 91.23 \\
\hline & $\begin{array}{l}\text { Daily average air temperature - } \\
\text { transition above }+5\end{array}$ & 115.19 \\
\hline & $\begin{array}{l}\text { Daily average air temperature - } \\
\text { transition above }+10\end{array}$ & 136.45 \\
\hline & Frost; last & 139.86 \\
\hline & Frost; soil; last & 142.44 \\
\hline & $\begin{array}{l}\text { Daily average air temperature - } \\
\text { transition above }+15\end{array}$ & 160.29 \\
\hline & $\begin{array}{l}\text { Daily minimal air temperature - } \\
\text { transition above }+10\end{array}$ & 165.44 \\
\hline & $\begin{array}{l}\text { Daily average air temperature - } \\
\text { transition more low }+15\end{array}$ & 234.26 \\
\hline & $\begin{array}{l}\text { Daily minimal air temperature - } \\
\text { transition more low }+10\end{array}$ & 234.83 \\
\hline & Frost; soil; 1st & 253.34 \\
\hline & Frost; 1st & 259.51 \\
\hline & $\begin{array}{l}\text { Daily average air temperature - } \\
\text { transition more low }+10\end{array}$ & 264.52 \\
\hline & $\begin{array}{l}\text { Daily average air temperature - } \\
\text { transition more low }+5\end{array}$ & 285.69 \\
\hline & $\begin{array}{l}\text { Daily average air temperature - } \\
\text { transition more low } 0\end{array}$ & 303.48 \\
\hline \multirow[t]{7}{*}{ Snow } & Snow cover melted & 114.60 \\
\hline & Snow cover melted; open spaces & 115.25 \\
\hline & Snow cover melted; forest & 123.08 \\
\hline & Snowfall; last & 125.66 \\
\hline & Snow cover formation; 1 st & 295.66 \\
\hline & Snow cover formation; permanent & 308.57 \\
\hline & Snowfall; 1st & 283.16 \\
\hline \multirow[t]{3}{*}{ Ice } & Ice cover melting; breakup & 116.33 \\
\hline & Ice cover melted & 120.27 \\
\hline & Ice formation; definitive & 319.39 \\
\hline \multirow{2}{*}{ Others } & Rain; 1st & 94.58 \\
\hline & Thunderstorm; 1st & 134.92 \\
\hline
\end{tabular}




\section{Text S2. Description of the HMSC model}

Hierarchical Modelling of Species Communities (HMSC) is a multivariate generalized linear mixed modelling framework ${ }^{2,3}$. HMSC was primarily developed for community ecology, so that in a typical application the response matrix $(\mathbf{Y})$ contains species occurrences or abundances on a set of sampling units (e.g. spatial locations), the environmental predictor matrix $(\mathbf{X})$ contains e.g. climatic conditions in those sampling units, and the species trait matrix (T) includes species-level traits such as body size. HMSC allows to ask how species occurrences depend on environmental conditions (how $\mathbf{Y}$ depends on $\mathbf{X}$ ), and how the species responses to environmental variation depend on their traits (how $\mathbf{T}$ modulates the mapping from $\mathbf{X}$ to $\mathbf{Y}$ ). Additionally, HMSC includes community-level random effects implemented through latent variables; these allow the modelling of residual (not accounted for species responses to $\mathbf{X}$ ) species associations at different spatiotemporal levels.

Here, we apply HMSC to phenological data, so that instead of species occurrences we include in the response matrix $\mathbf{Y}$ the dates of the phenological events. In other words, phenological events (e.g. the first arrival of a given bird species) here play the role of "species". In the predictor matrix $\mathbf{X}$, we include the climatic conditions of the study locations, as well as the year of the observation, with the latter capturing the trends over time that are the main focus of this paper. In the species trait matrix $\mathbf{T}$, we include key characteristics of the phenological events: the mean timing of the event (e.g. to distinguish spring events from autumn events), and the type of event (e.g. to distinguish abiotic from biotic events).

We call a given site-year pair as "sampling unit", and denote by $y_{i j}$ the date at which the phenological event $j$ took place in sampling unit $i$. Each data point is then the vector $y_{i}$, where the dot notation stands for the vector of $y_{i j}$ values for all indices $j$, thus $y_{i}$. consisting of the dates at which all phenological events took place for the site-year pair $i$. We modelled the data with the multivariate hierarchical linear mixed model defined as:

$$
y_{i j}=\sum_{k} x_{i k} \beta_{k j}+a_{s(i) j}+b_{t(i) j}+c_{i j}+\varepsilon_{i j} .
$$

- Concerning the fixed effects, $\beta_{k j}$ is the effect of the covariate $k$ on the phenological event $j$. The covariates included for each sampling unit $i$ were the year, the climatic descriptor of the site, and the interaction between these two. Additionally the model includes the intercept, so $x_{1 i}=1$ for all $i$.

- Concerning the community-level random effects, $s(i)$ denotes the site and $t(i)$ denotes the year of the sampling unit $i$. Thus $a_{s(i) j}$ is the random effect of the site, $b_{t(i) j}$ is the random effect of the year, and $c_{i j}$ is the random effect of the sampling unit. Each of these is modelled through the latent variable model described in detail in ${ }^{2}$, so that e.g. $a_{s j}=\sum_{h=1}^{n_{f}^{s}} \lambda_{h j}^{S} \eta_{h s}^{s}$, where $n_{f}^{s}$ is the number of factors included at the site level (as indicated by the superscript $s$ ), $\eta_{s k}^{s}$ is the latent variable $k$ for site $s$, and $\lambda_{k j}^{s}$ is the loading of phenological event $j$ for factor $k$. We note that the association matrix among the phenological events can be constructed from the loadings $\lambda_{k j}^{S}$ as $\Omega_{j_{1} j_{2}}^{s}=\sum_{h=1}^{n_{f}^{s}} \lambda_{h j_{1}}^{s} \lambda_{h j_{2}}^{s} ;$ see $^{2}$.

- Concerning the residual, we assume a linear model, so $\varepsilon_{i j} \sim N\left(0, \sigma_{j}^{2}\right)$, where $\sigma_{j}^{2}$ is the residual variance of phenological event $j$.

The responses of the phenological events to the covariates were further modelled with a linear regression, using the traits of the events as predictors. The expected response $\mu_{k j}=\mathrm{E}\left[\beta_{k j}\right]$ was modelled as $\mu_{k j}=\sum_{l} t_{j l} \gamma_{k l}$ and the realized response with the multivariate normal model as 
$\beta \cdot j \sim N\left(\mu_{k}, \mathbf{V}\right)$. As the trait predictors $t_{j h}$, we included the intercept, the mean day of the phenological event, the type of the phenological event, and the interaction between them. To account for the periodic nature of the day of the year, the mean day of the phenological event $d$ was modelled with the predictors $\cos (2 \pi d / 356)$ and $\sin (2 \pi d / 356)$. The type of event was implemented as a factor, with the levels of abiotic events, producers, primary consumers, secondary consumers, and saprotophs.

We fitted the models with R-package $\mathrm{Hmsc}^{4}$ assuming the default prior distribution. For a technical description of the default prior distribution we refer to ${ }^{4}$, whereas for an ecological motivation of the default prior distribution we refer to ${ }^{2}$. We performed posterior sampling for four Markov Chain Monte Carlo (MCMC) chains, each of which we sampled for 375,000 iterations, out of which we discarded the first 125,000 as a transient and thinned the remaining by 1000 , thus yielding 250 samples per chain and 1000 samples in total. To evaluate MCMC convergence, we examined the distributions of the potential scale reduction factor over the parameters related to the fixed effects ( $\beta$-parameters) and the random effects ( $\Omega$-parameters), equivalent to the Gelman-Rubin statistic ${ }^{5}$. 


\section{Text S3. Convergence of the Markov chain Monte Carlo (MCMC) scheme used for posterior sampling}

For each model we obtained 250 samples for each of the four MCMC chains, and thus in total 1000 samples. The 250 samples for each chain were obtained by running the MCMC for $375^{*}$ thin iterations, out of which $125 *$ thin were discarded as transient, and the remaining $250 *$ thin iterations were then evenly thinned to yield 250 samples. We applied thin=1, 10, 100, 1000 to check which level of thinning was sufficient to ensure satisfactory convergence. We assessed MCMC convergence by computing the effective number of samples and the potential scale reduction factor. These are shown in Fig. S3 for the beta-parameters of the HMSC model $^{4}$, which parameters measure the responses of the species to the included covariates. As the majority of the potential scale reduction factors are close to one and the effective sample size is close to the actual sample size of 1000 , we conclude the MCMC convergence was satisfactory.

\section{Figure S1. MCMC convergence statistics, measured as potential scale reduction factors and effective sample sizes.}

Each boxplot shows the distribution of values over the species-specific beta-parameters for models that include the mean annual temperature (T), latitude (L), photoperiod (P) or chilling sum $(\mathrm{C})$ as the climatic predictor.
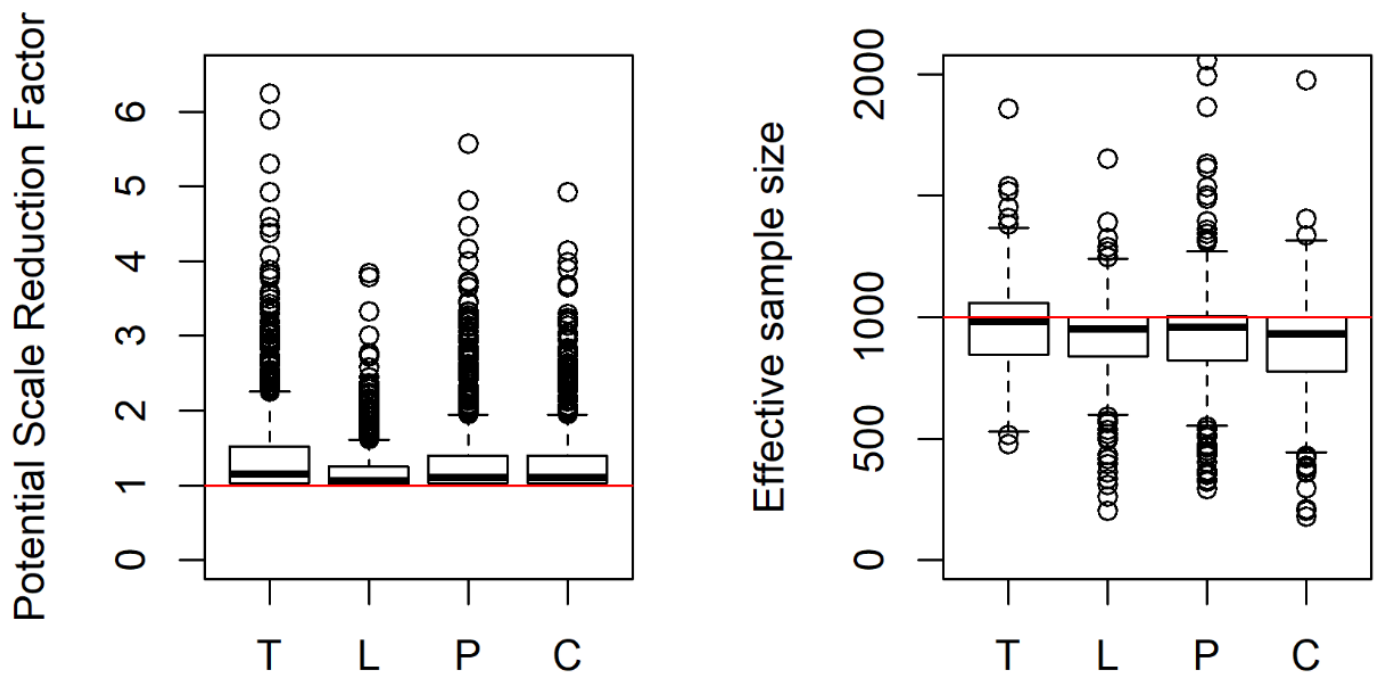


\section{References}

1. White, T. C. R. When is a herbivore not a herbivore ? Oecologia 67, 596-597 (1985).

2. Ovaskainen, O. \& Abrego, N. Joint Species Distribution Modelling With Applications in R. ( Cambridge University Press , 2020).

3. Ovaskainen, O. et al. How to make more out of community data? A conceptual framework and its implementation as models and software. Ecology Letters 20, 561-576 (2017).

4. Tikhonov, G. et al. Joint species distribution modelling with the R-package HMSC. Methods in Ecology and Evolution 11, 442-447 (2019).

5. Gelman, A. et al. Bayesian Data Analysis. (2013). 